\title{
Treatment with the CC chemokine-binding protein Evasin-4 improves post-infarction myocardial injury and survival in mice
}

\author{
Vincent Braunersreuther ${ }^{1 *}$; Fabrizio Montecucco ${ }^{1,2 *}$; Graziano Pelli'; Katia Galan'; Amanda E. Proudfoot ${ }^{3}$; Alexandre Belin 4 ; \\ Nicolas Vuilleumier ${ }^{5,6}$; Fabienne Burger'; Sébastien Lenglet ${ }^{1}$; Irene Caffa ${ }^{2}$; Debora Soncini ${ }^{2}$; Alessio Nencioni' ${ }^{2}$ Jean-Paul Vallée ${ }^{4 \# \text {; }}$ \\ François Mach ${ }^{1 \#}$ \\ ${ }^{1}$ Division of Cardiology, Foundation for Medical Researches, Faculty of Medicine, Department of Internal Medicine, Geneva University Hospital, Geneva, Switzerland; ${ }^{2}$ First Clinic \\ of Internal Medicine, Department of Internal Medicine, University of Genoa School of Medicine, IRCCS Azienda Ospedaliera Universitaria San Martino-IST Istituto Nazionale per \\ la Ricerca sul Cancro, Genoa, Italy; ${ }^{3}$ Merck Serono Geneva Research Centre, Geneva, Switzerland; ${ }^{4}$ Department of Radiology - CIBM, Geneva, University Hospital, Geneva, \\ Switzerland; ${ }^{5}$ Division of Laboratory Medicine, Department of Genetics and Laboratory Medicine, Geneva University Hospitals, Switzerland; ${ }^{6}$ Department of Human Protein Science, \\ Geneva Faculty of Medicine, Geneva, Switzerland
}

\begin{abstract}
Summary
Chemokines trigger leukocyte trafficking and are implicated in cardiovascular disease pathophysiology. Chemokine-binding proteins, called "Evasins" have been shown to inhibit both CC and CXC chemokinemediated bioactivities. Here, we investigated whether treatment with Evasin-3 (CXC chemokine inhibitor) and Evasin-4 (CC chemokine inhibitor) could influence post-infarction myocardial injury and remodelling. C57Bl/6 mice were submitted in vivo to left coronary artery permanent ligature and followed up for different times (up to 21 days). After coronary occlusion, three intraperitoneal injections of $10 \mu \mathrm{g}$ Evasin-3, $1 \mu \mathrm{g}$ Evasin-4 or equal volume of vehicle (PBS) were performed at 5 minutes, 24 hours (h) and $48 \mathrm{~h}$ after ischaemia onset. Both anti-chemokine treatments were associated with the beneficial reduction in infarct size as compared to controls. This effect was accompanied by a decrease in post-infarction myocardial leukocyte infiltration, reactive oxygen species release, and circulating levels of
\end{abstract}

Correspondence to:

Fabrizio Montecucco, MD, PhD

Cardiology Division, Department of Medicine

Geneva University Hospital, Foundation for Medical Researches

64 Avenue Roseraie, 1211 Geneva, Switzerland

Tel.: +41 223827238, Fax: +41 223827245

E-mail: Fabrizio.montecucco@unige.ch

* These authors contributed equally as first authors.

\# These authors contributed equally as last authors.
CXCL1 and CCL2. Treatment with Evasin-4 induced a more potent effect, abrogating the inflammation already at one day after ischaemia onset. At days 1 and 21 after ischaemia onset, both anti-chemokine treatments failed to significantly improve cardiac function, remodelling and scar formation. At 21-day follow-up, mouse survival was exclusively improved by Evasin-4 treatment when compared to control vehicle. In conclusion, we showed that the selective inhibition of CC chemokines (i.e. CCL5) with Evasin-4 reduced cardiac injury/inflammation and improved survival. Despite the inhibition of CXC chemokine bioactivities, Evasin-3 did not affect mouse survival. Therefore, early inhibition of CC chemokines might represent a promising therapeutic approach to reduce the development of post-infarction heart failure in mice.

\section{Keywords}

Chemokines, neutrophils, inflammation, acute myocardial infarction

Received: April 10, 2013

Accepted after major revision: July 3, 2013

Prepublished online: August 8, 2013

doi:10.1160/TH13-04-0297

Thromb Haemost 2013; 110: 807-825

\section{Introduction}

Chronic ischaemia has been shown to induce adverse major structural and functional changes within the myocardium in both animal models and humans $(1,2)$. During its evolution, cardiac remodelling during chronic ischaemia might involve several pathophysiological mechanisms (such as cardiomyocyte death, release of reactive oxygen species [ROS] and proteases, modifications of extracellular matrix, fibrosis, and inflammation), underlying postischaemic heart failure and potential arrhythmias $(3,4)$. Similarly to acute myocardial ischaemia and reperfusion, in chronic myocardial ischaemia, the inflammatory cell infiltration and activation is a natural event essential for dead cell and debris clearing and tissue reparation allowing scar formation $(4,5)$. Leukocyte recruitment from the blood stream within the infarcted myocardium is driven by the establishment of a chemotactic gradient towards inflamed tissues (6). In particular, the post-ischaemic release of CXC and CC chemokines is timely regulated and differently influences leukocyte infiltration depending on the post-ischaemic phase $(3,6$, 7). Recent evidence suggested that the early modulation of the bioactivities of certain leukocyte chemoattractants (such as CCL5 and CXCL12) might prevent adverse cardiac remodelling and left ventricular dysfunction $(3,8)$. These beneficial effects were associated with a reduced leukocyte infiltration and protease release 
within the infarcted myocardium, thus improving post-infarction outcomes $(3,8)$. Considering promising results from recent treatment strategies selectively inhibiting CC or CXC chemokine pathways $(3,7)$, we focused on small chemokine-binding proteins called "Evasins" (9). These molecules, isolated from the tick salivary glands, where they help to evade host immune defense (10), were recently produced as recombinant molecules (9). Importantly, Evasins showed potent anti-inflammatory properties in experimental models of inflammatory diseases, such as antigen-induced arthritis (9), colitis (11), graft versus host-disease (12), and in bleomycin-induced pulmonary fibrosis (13). Moreover, treatments with Evasin-3 have been shown to reduce neutrophil-mediated injury in a mouse model of myocardial reperfusion injury and carotid atherosclerosis $(7,14)$. In this study, we aimed at investigating the potential beneficial effects of chronic treatments with Evasin-3 (which inhibits the neutrophil attractants ELR-CXC chemokines, such as CXCL1 and CXCL2) or Evasin-4 (which inhibits several pro-inflammatory CC chemokines including CCL5 and CCL11) (9) in a mouse model of chronic myocardial ischaemic injury, post-ischaemic adverse remodelling and final heart failure.

\section{Material and methods In vivo cardiac chronic ischaemia protocol}

Male C57Bl/6 mice (8-12 weeks of age) were obtained from the University Medical Centre (CMU) animal facility, Medical Faculty, University of Geneva, Geneva, Switzerland. The investigation conforms to the Guide for the Care and Use of Laboratory Animals published by the US National Institutes of Health (NIH Publication No. 85-23, revised 1996) and has been approved by Swiss Regulatory and Ethical Authorities. This mouse protocol conformed to the "position of the American Heart Association on Research Animal Use".

Mice were initially anaesthetised with $4 \%$ isoflurane and intubated. After starting mechanical ventilation (tidal volume of 150 $\mathrm{ml}, 120$ breaths/minute [min]) anesthesia was maintained with $2 \%$ isoflurane, supplemented with $100 \%$ oxygen. Then, a thoracotomy was performed in the left third intercostal space and the pericardium was removed. Ligature of the left anterior coronary artery at the inferior edge of the left atrium was performed using an 8-0 Prolene suture. The coronary occlusion was maintained till animal sacrifice. At $5 \mathrm{~min}, 24$ hours (h) and $48 \mathrm{~h}$ after left coronary occlusion, either Evasin-3 (10 $\mu \mathrm{g})$, Evasin-4 $(1 \mu \mathrm{g})$ or equivalent volume of vehicle (phosphate-buffered saline [PBS], $200 \mu \mathrm{l}$ ) were intraperitoneally administered. The doses of Evasin- 3 and Evasin- 4 administered were based on previous studies, showing marked efficacy to reduce in vivo neutrophil infiltration within inflamed tissues $(7,9,14)$. After the first administration, the chest was closed and the tube removed from trachea to restore normal respiration. Sham-operated animals were submitted to the same surgical protocol as described but without coronary occlusion. At different time points of chronic ischaemia (from 1 to 21 days), animals were euthanized for infarct size determination, immunohistochemical analysis, or serum enzyme-linked immunosorbent assay (ELISA).
In vivo magnetic resonance imaging (MRI) was performed in animals without surgery and after chronic ischaemia (at 1 and 21 days after ischaemia onset) under different treatments.

\section{Area at risk (AAR) and infarct size (I) assessment}

To assess area at risk (AAR) and infarct size (I), mice were euthanised with ketamine-xylazine and sacrificed at day 1 of chronic ischaemia, as previously described (7). Evan's blue dye (2\%; Sigma, St. Louis, MO, USA) was injected in the left ventricle to dellineate the in vivo AAR. The heart was rapidly excised and rinsed in $\mathrm{NaCl}$ $0.9 \%$. Then, hearts were frozen and sectioned into $2-\mathrm{mm}$ transverse sections from the apex to the base (5-6 slices/heart). The sections were, incubated at $37^{\circ} \mathrm{C}$ with $1 \%$ triphenyltetrazolium chloride (TTC) in phosphate buffer (pH 7.4) for $15 \mathrm{~min}$, fixed in 4\% formaldehyde solution and photographed with a digital camera (Nikon Coolpix) to distinguish continuously perfused tissue (blue), stained ischaemic viable tissue (red) and unstained necrotic tissue (white). The different zones were determined using MetaMorph software (version 6.0, Universal Imaging Corporation, Downingtown, PA, USA). AAR and left ventricular infarct zone (I) were expressed as percentages of total ventricle surface (AAR/V) and AAR (I/AAR), respectively. In selective experiments, nitrobluetrazolium chloride (NBT, to identify metabolically inactive tissues) staining was performed in heart 7- $\mu \mathrm{m}$ sections at 7 and 21 days of chronic ischaemia, as classically described. Infarct size (IS) was determined as the NBT-negative area (15). These data were expressed as percentages of infarct zone on total ventricle surface.

\section{Western blot analysis}

After 15 min of in vivo chronic ischaemia, mouse hearts were excised and proteins were extracted in lysis buffer containing $50 \mathrm{mM}$ Tris- $\mathrm{HCl} \mathrm{pH}$ 8.0, $150 \mathrm{mM} \mathrm{NaCl}, 1 \% \mathrm{NP} 40,0.05 \%$ SDS, $10 \mathrm{mM}$ $\mathrm{NaF}, 1 \mathrm{mM}$ PMSF, $2 \mathrm{mM} \mathrm{Na}_{3} \mathrm{VO}_{4}$, and complete protease inhibitor cocktail tablet (Roche, Basel, Switzerland). Proteins (50 $\mu \mathrm{g}$ per lane) were electrophoresed through polyacrylamide/SDS gels and transferred by electroblotting onto PVDF membranes. Membranes were blocked for $1 \mathrm{~h}$ in $5 \%(\mathrm{w} / \mathrm{v})$ nonfat milk before $\mathrm{O} / \mathrm{N}$ incubation with appropriate dilutions of primary phospho-specific anti-mouse ERK 1/2 (R\&D Systems, Minneapolis, MN, USA), or anti-mouse STAT-3 serine 472 or tyrosine 705 antibodies (both from Cell Signaling Technology, Danvers, MA, USA), as well as corresponding secondary antibodies. The blots were developed using the ECL system (Immobilion ${ }^{\text {tw }}$ Western, Millipore, Billerica, MA, USA). To verify equal loading of the total proteins, membranes were stripped (for $15 \mathrm{~min}$ at $50 \mathrm{C}$ in Tris-HCL pH 6.7, 2\% SDS and $0.1 \mathrm{M} \beta$-mercaptoethanol), reblocked and reprobed to detect total ERK 1/2 (R\&D Systems) or STAT-3 (Cell Signaling Technology). Relative intensities were calculated by dividing the phosphorylated protein through the total protein. 


\section{Human peripheral blood mononuclear cell (PBMC) isolation and culture}

PBMCs (>75\% CD3+ lymphocytes) were isolated from blood samples obtained from eight healthy donors by Ficoll-Hypaque density gradient centrifugation, as previously described (16). The local ethical committee approved the investigation protocol, and it was conformed to the principles outlined in the Declaration of Helsinki. Then, cells were resuspended in culture medium (RPMI 1640 plus fetal bovine serum $10 \%$, penicillin $[10,000 \mathrm{U} / \mathrm{ml}]$ and streptomycin $[10,000 \mu \mathrm{g} / \mathrm{ml}])$ for the stimulation. A total of $3 \times 10^{6}$ human PBMCs/well were incubated in 24-well plates in the presence or absence of $25 \mathrm{ng} / \mathrm{ml}$ phorbol myristate acetate (PMA)/0.5 $\mu \mathrm{M}$ ionomycin (I) (positive control) or human recombinant CCL5 $(0.01 ; 0.1 ; 1 ; 10 ; 100 \mathrm{ng} / \mathrm{ml})$. Twenty-four hours later, supernatants were collected, aliquoted and stored at $-80^{\circ} \mathrm{C}$ for Enzyme-Linked Immunosorbent Assay (ELISA) determination of CCL5, CXCL1 and CCL2. ELISA experiments were performed following manufacturer's instructions (R\&D Systems). The limit of detection was $15.6 \mathrm{pg} / \mathrm{ml}$ for human CCL5, $31.2 \mathrm{pg} / \mathrm{ml}$ for human CXCL1, and $15.6 \mathrm{pg} / \mathrm{ml}$ for human CCL2. Mean intra- and inter-assay coefficients of variation $(\mathrm{CV})$ were below $6 \%$ for all mediators.

\section{Serum chemoattractant level detection}

Serum CXCL1, CXCL2, CCL2, CCL3, CCL5 and CCL11 levels were measured in mouse sera at day 1 in sham-operated mice and at days 1 and 7 of chronic ischaemia by colourimetric ELISA, following manufacturer's instructions (R\&D Systems). The limit of detection was $15.6 \mathrm{pg} / \mathrm{ml}$ for CXCL1, $7.8 \mathrm{pg} / \mathrm{ml}$ for CXCL2, 15.6 $\mathrm{pg} / \mathrm{ml}$ for CCL2, $4.7 \mathrm{pg} / \mathrm{ml}$ for CCL3, $7.8 \mathrm{pg} / \mathrm{ml}$ for CCL5, $15.6 \mathrm{pg} /$ $\mathrm{ml}$ for CCL11. Mean intra- and inter-assay coefficients of variation (CV) were below $6 \%$ for all mediators.

\section{Immunostaining}

Hearts from animals sacrificed after days 1 and 7 of chronic ischaemia were frozen in optimal cutting temperature compound (OCT) and serially cut from the occlusion locus to the apex in $7-\mu \mathrm{m}$ sections. Immunostainings for neutrophils (anti-mouse Ly-6B.2 Ab, dilution 1:50; ABD Serotec, Dusseldorf, Germany), macrophages (anti-mouse CD68 Ab, dilution: 1:400; ABD Serotec), mouse MMP-9 (anti-mouse MMP-9 Ab, dilution: 1:60; R\&D Systems), mouse MMP-8 (anti-mouse MMP-8 Ab, dilution: 1:50; Santa Cruz Biotechnology, Santa Cruz, CA, USA) were performed on five midventricular cardiac sections per animal, and quantification performed with the MetaMorph software, as previously described (7).

\section{Oxidative stress determination}

Measurement of superoxide in myocardium submitted to chronic ischaemia was performed using the superoxide-sensitive dye dihydroethidium (DHE, Molecular Probes, Eugene, OR, USA). Intracellular oxidative factors oxidise non-fluorescent DHE to fluor- escent ethidium and 2-hydroxyethidium. The formation of ethidium and 2-hydroxyethidium, DNA intercalators, can be monitored by measuring its accumulation within the cell nucleus. Five frozen midventricular cardiac sections per animal (euthanised after $24 \mathrm{~h}$ of chronic ischaemia) were stained with $10 \mu \mathrm{M} \mathrm{DHE}$ at $37^{\circ} \mathrm{C}$ for 30 min in a light-protected and humidified chamber. Then, nuclei were stained with 4',6-diamidino-2-phenylindole (DAPI). In situ fluorescence was assessed using fluorescence microscopy and quantification performed with MetaMorph software. The production of ROS has been assessed by two histological mediators: the highly toxic product of lipid membrane peroxidation 4-hydroxy2-nonenal (mouse anti-4-HNE monoclonal antibody at $1 \mu \mathrm{g} / \mathrm{ml}$; Oxis International Inc, Foster City, CA, USA) and the 3,5-dibromotyrosine (mouse anti-Di bromo tyrosine monoclonal antibody at $10 \mu \mathrm{g} / \mathrm{ml}$, AMS biotechnology, LTD, Abingdon, UK) (16). To avoid any potential cross-reactivity with mouse heart antigens and to increase the specificity of the primary antibodies, the VECTOR M.O.M Immunodetection kit and the VECTOR VIP substrate kit for peroxidase (Vector Laboratories, Inc. Burlingame, CA, USA) were used, following the manufacturer's instructions. Quantification was performed with MetaMorph software. Results were expressed as percentages of stained area on total heart surface area.

\section{Determination of cardiac collagen content}

Two classical methods were used to determine cardiac collagen deposition at days 7 and 21 of chronic ischaemia: Masson's Trichrome and Sirius red stainings. Masson's Thrichrome staining was performed as previously described (17). For Sirius red staining, five mid-ventricular sections per mouse heart were rinsed with water and incubated with $0.1 \%$ Sirius red (Sigma) in saturated picric acid for $90 \mathrm{~min}$, as previously described (3). Then sections were photographed with identical exposure settings each section under ordinary polychromatic or polarised light microscopy. Total collagen content was evaluated under polychromatic light (Sirius red). Interstitial collagen subtypes were evaluated using polarised light illumination; under this condition thicker type I collagen fibers appeared orange or red, whereas thinner type III collagen fibers were yellow or green (3). Quantifications were performed with MetaMorph software. Data were calculated as percentage of stained area per total lesional area.

\section{Magnetic resonance imaging (MRI)}

MRI was performed in mice without surgery and at days 1 and 21 of chronic myocardial ischaemia, as previously described (3). During the MRI exam, mouse anesthesia was maintained with isoflurane $2 \%$. Imaging was performed on a 3T MR scanner (Magnetom TIM Trio, Siemens Medical Solutions, Erlangen, Germany) with a dedicated two-channel mouse receiver coil (Rapid biomedical $\mathrm{GmbH}$, Rimpar, Germany). A turboflash cine sequence assessed myocardial function: FOV $66 \mathrm{~mm}$, in plane resolution $257 \mu \mathrm{m}$, slice thickness $1 \mathrm{~mm}, 5-7$ consecutive slices to cover the whole left ventricle (no slice overlap), TE/TR effective $6.5 / 6.8 \mathrm{~ms}$, flip angle 30 , GRAPPA with acceleration factor 2, 3 averages, typical acquisi- 


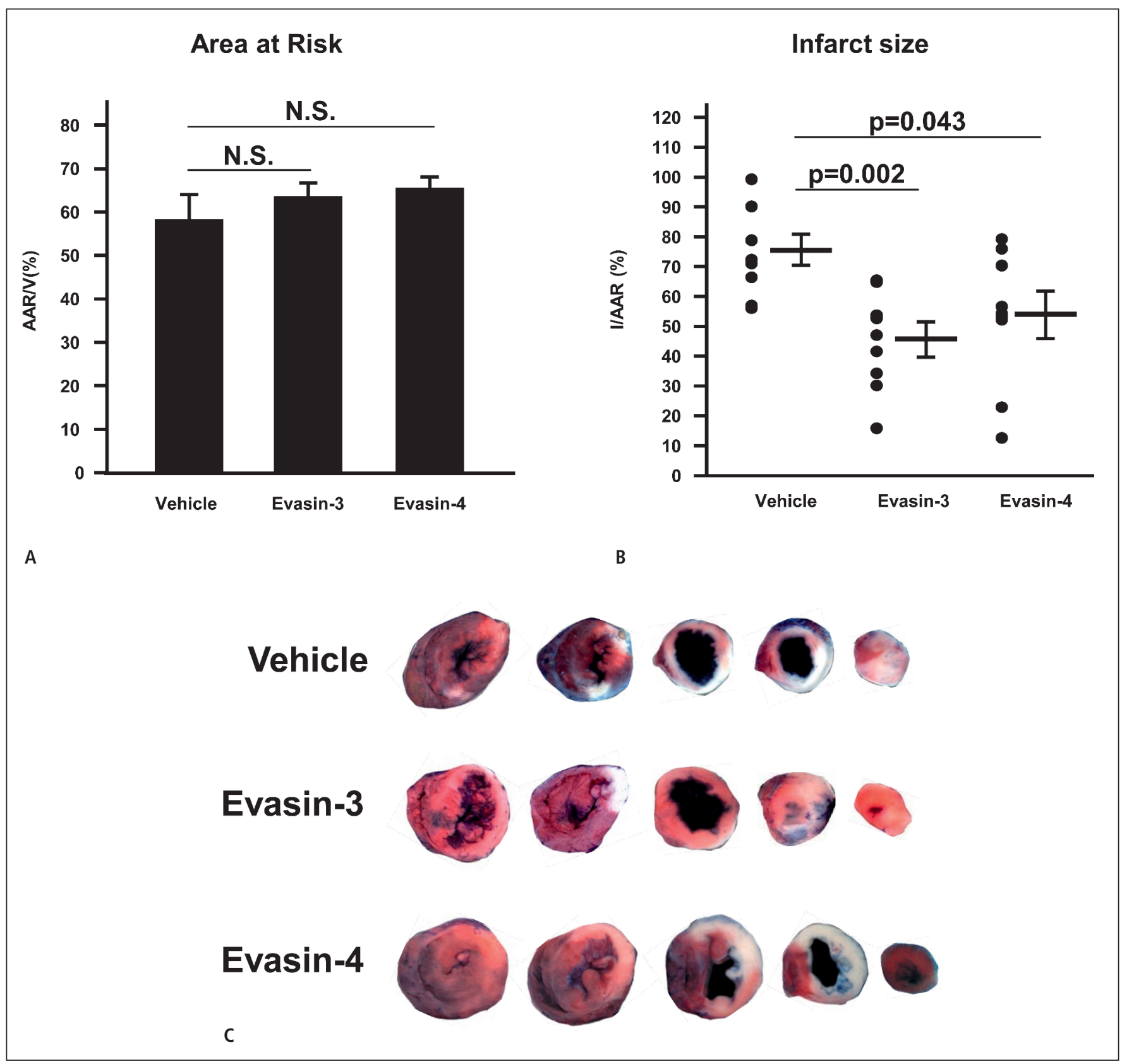

Figure 1: Single administration of Evasin-3 or Evasin-4 reduces infarct size in a mouse model of myocardial chronic ischaemia. Evasin-3 (10 $\mu \mathrm{g} /$ mouse), Evasin-4 (1 $\mu \mathrm{g} /$ mouse) or vehicle (PBS, $200 \mu \mathrm{l})$ were administered 5 min after ischaemia onset. Data are expressed as mean \pm SEM. A) Quantification of area at risk (AAR) per ventricle surface (V) after $24 \mathrm{~h}$ of chronic ischaemia ( $n=8-9$ per group). B) Quantification of infarct size (I) per AAR after $24 \mathrm{~h}$ of chronic ischaemia ( $\mathrm{n}=8-9$ per group). C) Representative images of TTC stained heart sections of vehicle- Evasin-3 or Evasin-4-treated mice. N.S.: not significant.
Figure 2: Treatment with Evasins does not affect protective intracellular pathways (ERK $1 / 2$ and STAT-3 phosphorylation) in infarcted hearts. A) Representative western blots of heart lysates ( $50 \mu \mathrm{g}$ per lane) of mice sham-operated (Sham) or treated with vehicle (Ve), Evasin-3 (Eva-3) or Evasin-4 (Eva-4) on ERK1/2 activation (phosphorylated and total protein) at 15 min of in vivo chronic ischaemia. B) Quantification of western blots on phospho (P)-ERK1 on total protein ( $n=3-5$ per group; mean \pm SEM; * $p<0.05$ vs vehicle. C) Quantification of western blots on P-ERK2 on total protein $\left(n=3-5\right.$ per group; mean \pm SEM; ${ }^{*} p<0.05$ vs vehicle. D) Representative west- ern blots of heart lysates ( $50 \mu \mathrm{g}$ per lane) of mice sham-operated (Sham) or treated with vehicle (Ve), Evasin-3 (Eva-3) or Evasin-4 (Eva-4) on STAT-3 activation (phosphorylated and total protein) at $15 \mathrm{~min}$ of in vivo chronic ischaemia. E) Quantification of western blots on Stat-3 phosphorylated on tyrosine (Tyr) 705 on total protein ( $n=3-5$ per group; mean $\pm S E M$; ${ }^{*} p<0.05$ vs vehicle. F) Quantification of western blots on Stat-3 phosphorylated on serine (Ser) 472 on total protein $(n=3-5$ per group; mean \pm SEM; N.S.: not significant. 


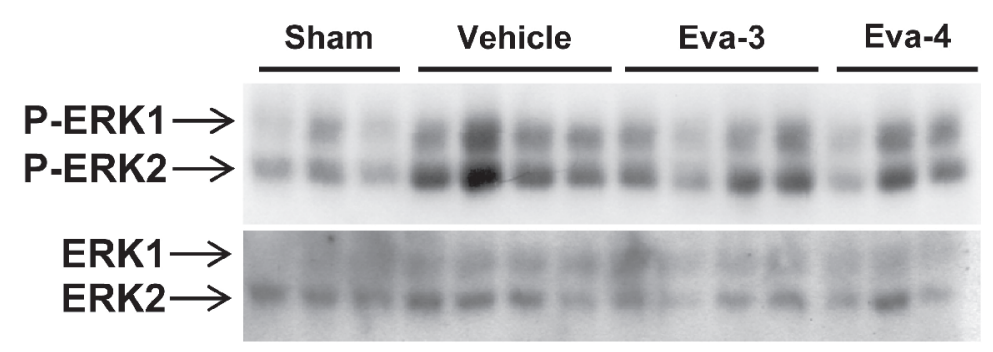

A
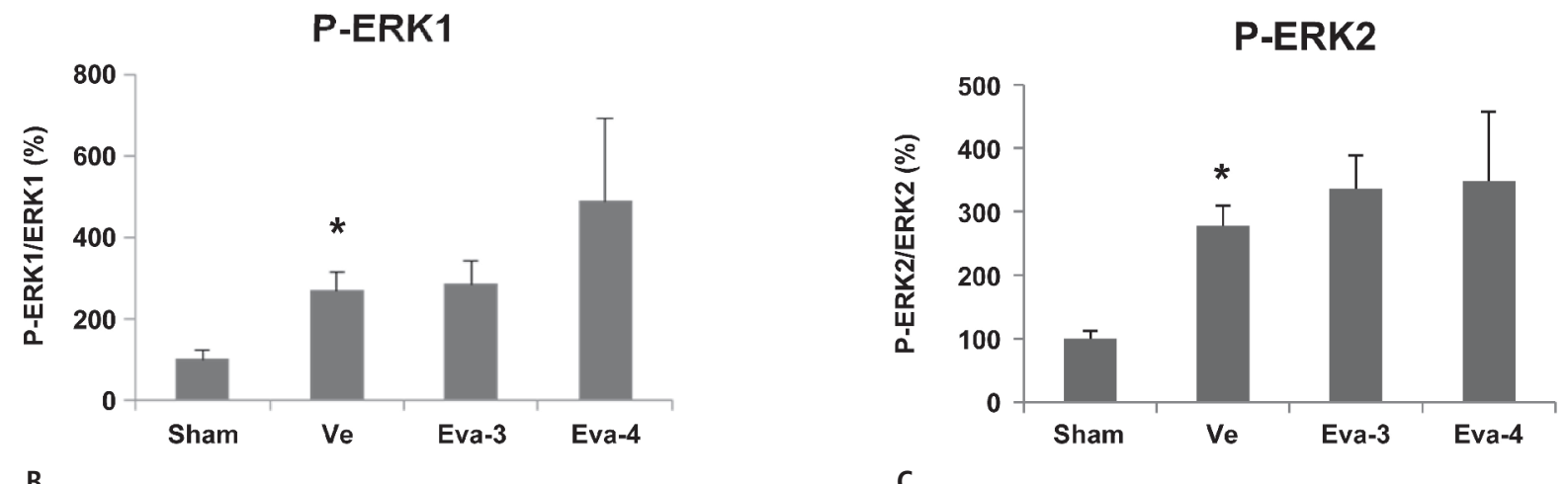

C

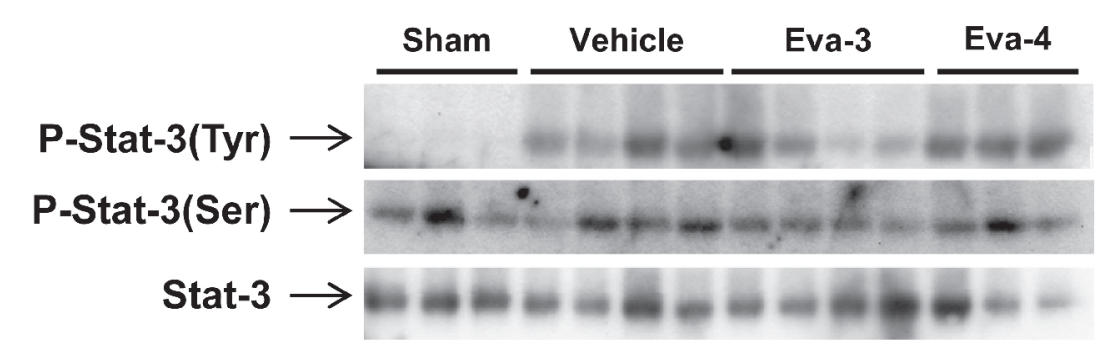

D

P-Stat-3(Tyr)

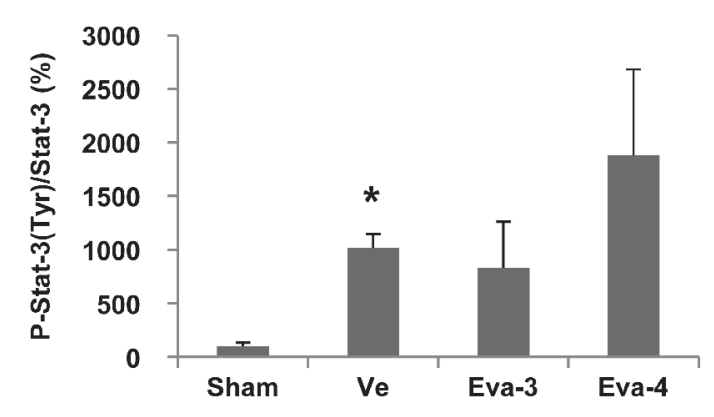

$E$

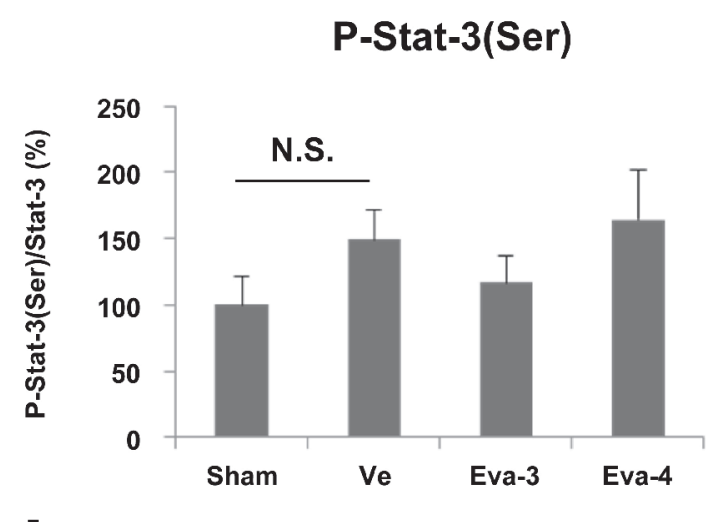

$\mathbf{F}$ 


\section{Serum profile of inflammatory chemokines}
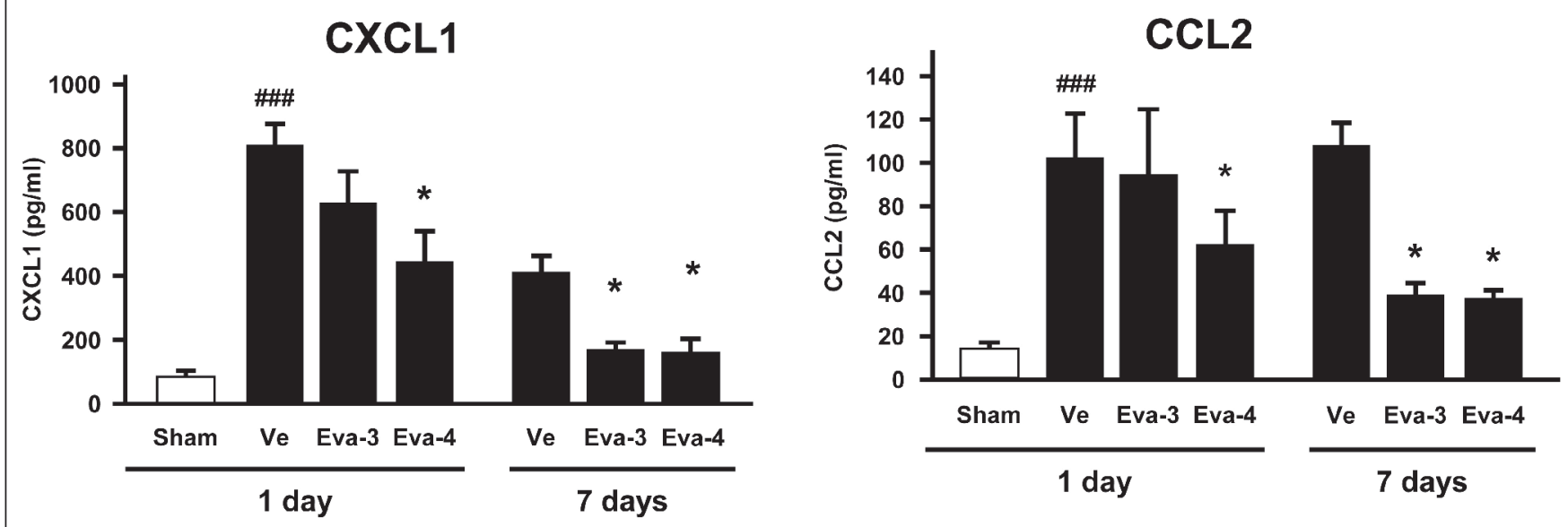

A

B
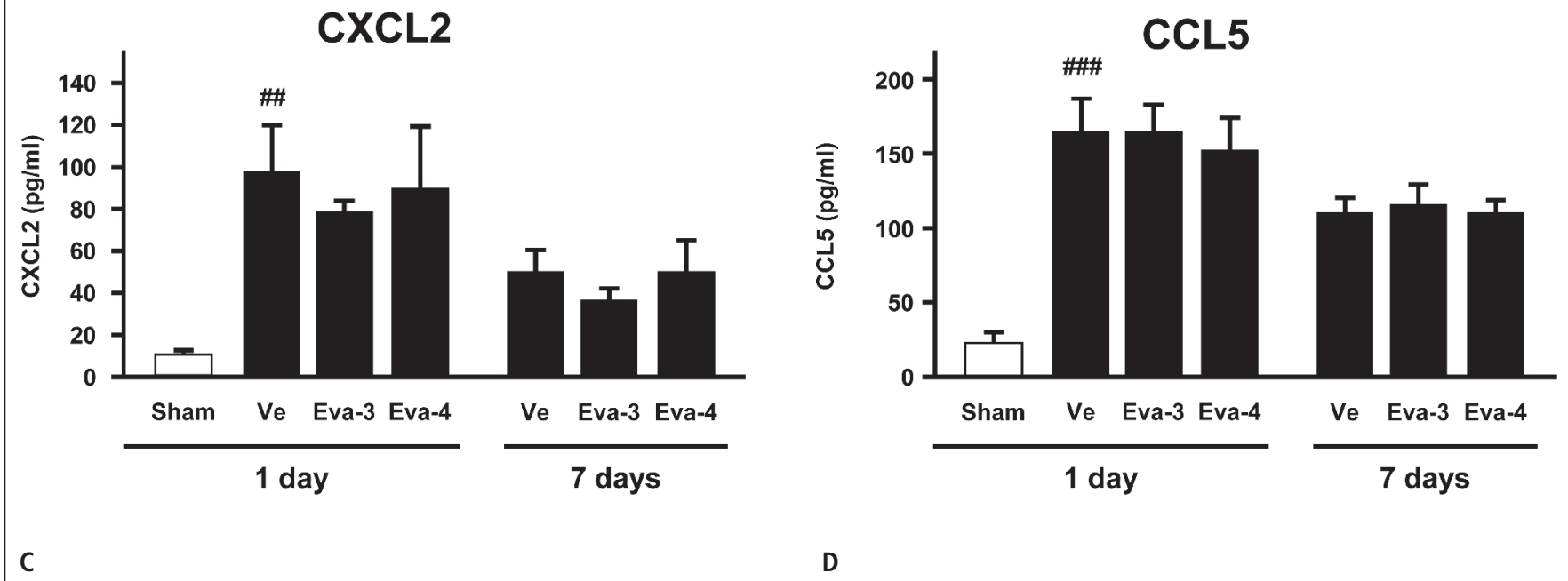

C

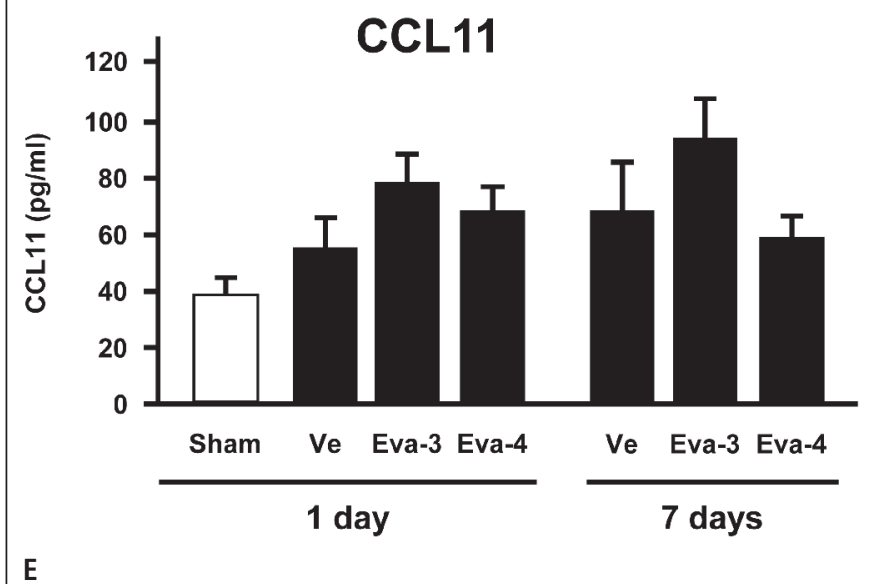

Figure 3: Treatments with Evasins reduce the serum levels of CXCL1 and CCL2 during chronic ischaemia. Serum levels of CXCL1, CXCL2 (neutrophil chemoattractants), CCL2, CCL5 (monocyte/macrophage chemoattractants) and CCL11 were measured 1 and 7 days after ischaemia onset in sham-operated (Sham), vehicle (Ve)-, Evasin-3 (Eva-3)- or Evasin-4 (Eva-4)-treated mice, respectively. Data are expressed as mean \pm SEM ( $n=4$ for Sham, $n=7-9$ for other groups). A) CXCL1. B) CCL2. C) CXCL2. D) CCL5. E) CCL11. \#\#p<0.01 vs Sham; \#\#\#p<0.001 vs Sham; ${ }^{*} p<0.05$ vs respective vehicle at days 1 and 7 . 
Figure 4: CCL5 stimulates the release of CXCL1 and CCL2 by peripheral blood mononuclear cells (PBMCs) in vitro. A) Human PBMCs (>75\% CD3+ lymphocytes) were incubated with control medium (CTL), or $25 \mathrm{ng} / \mathrm{ml}$ phorbol myristic acetate (PMA)/0.5 $\mu \mathrm{M}$ lonomycin (I) for $24 \mathrm{~h}$. Then, supernatants were collected for ELISA determination of CCL5 levels. Results are expressed as mean \pm SEM of independent experiments with eight donors. ${ }^{* * *} p<0.0001$ vs CTL. B-C) Human PBMCs were incubated with control medium (CTL), $25 \mathrm{ng} /$ $\mathrm{ml}$ phorbol myristic acetate (PMA) $/ 0.5 \mu \mathrm{M}$ lonomycin (I) or different concentrations of recombinant human $\mathrm{CCL} 5$ for $24 \mathrm{~h}$. Then, supernatants were collected for ELISA determination of CXCL1 (B) and CCL2 (C) levels. Results are expressed as mean \pm SEM of independent experiments with eight donors. ${ }^{* *} p<0.01$ vs $C T L ;{ }^{* * *} \mathrm{p}<0.001$ vs CTL.

\section{CCL5}

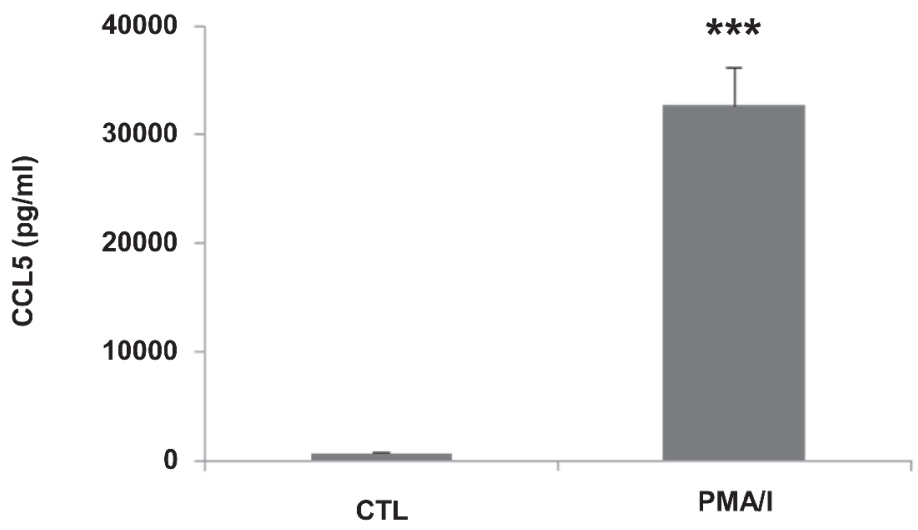

CXCL1

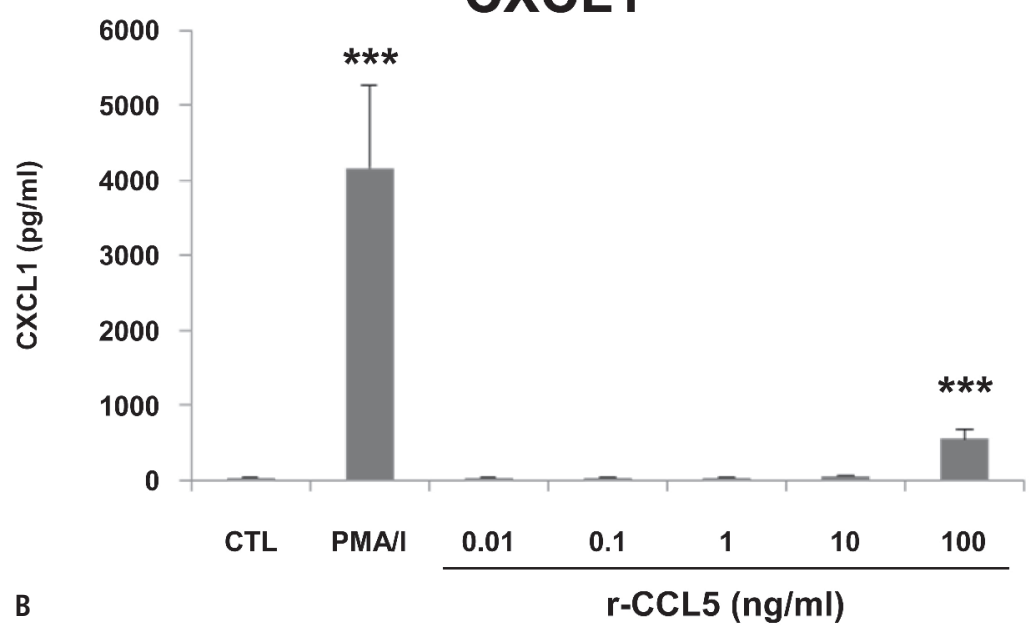

CCL2

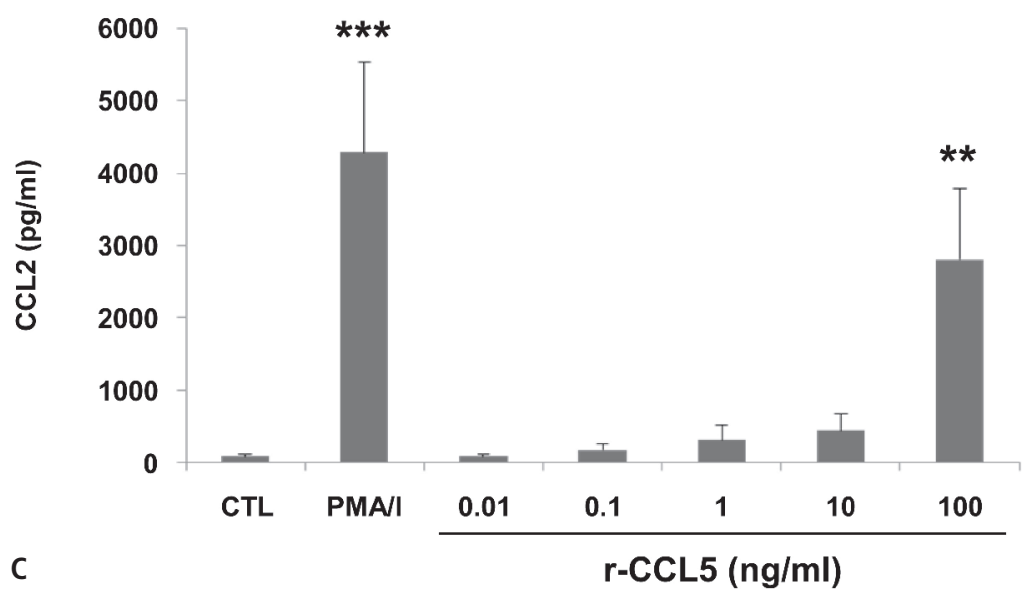




\section{Neutrophils}
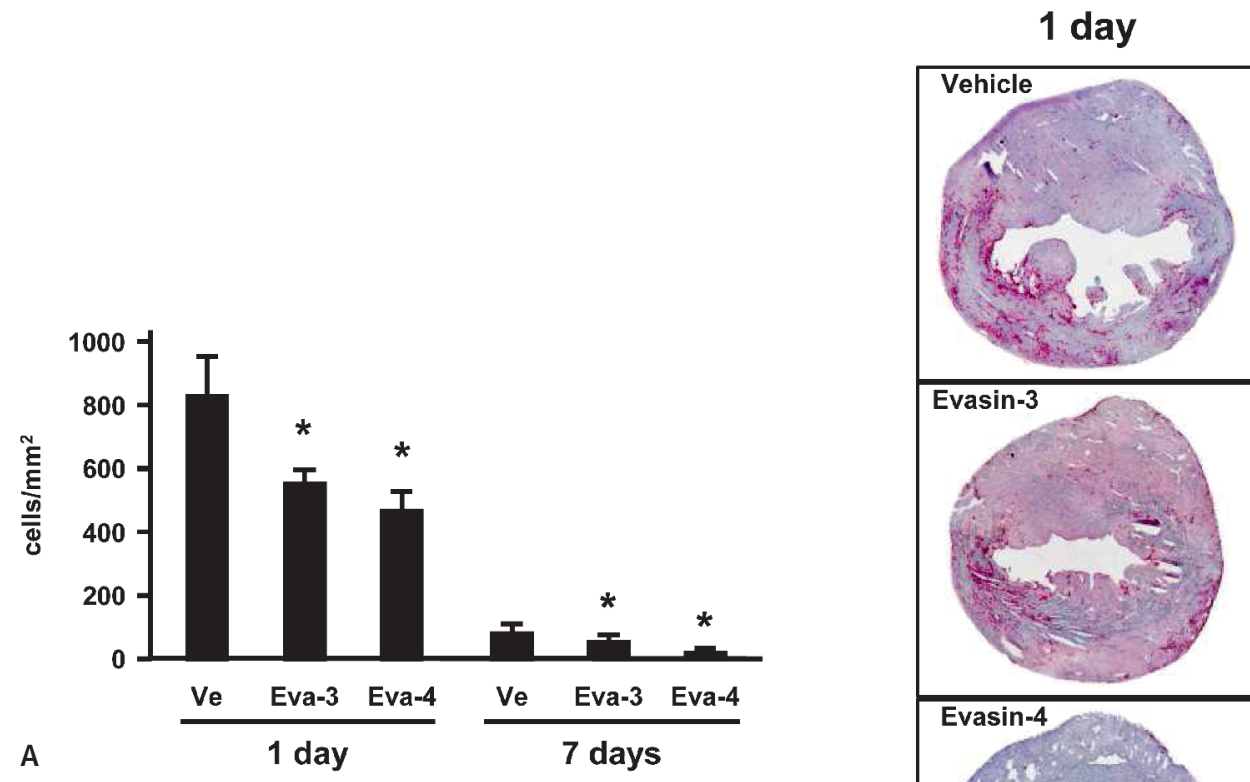

7 days

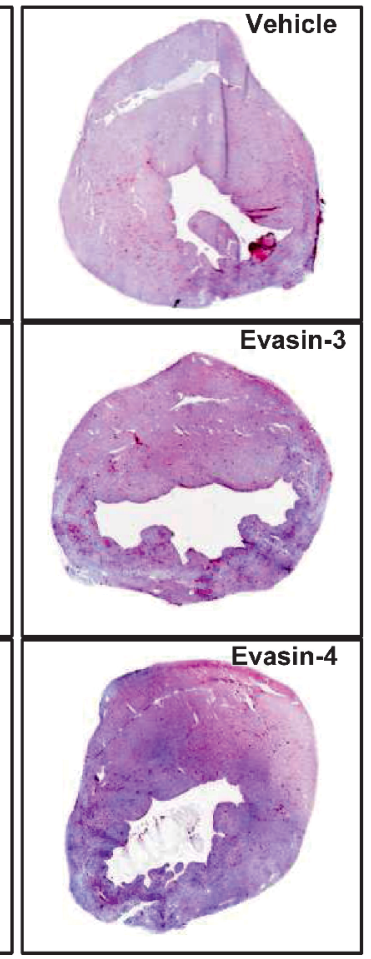

Macrophages
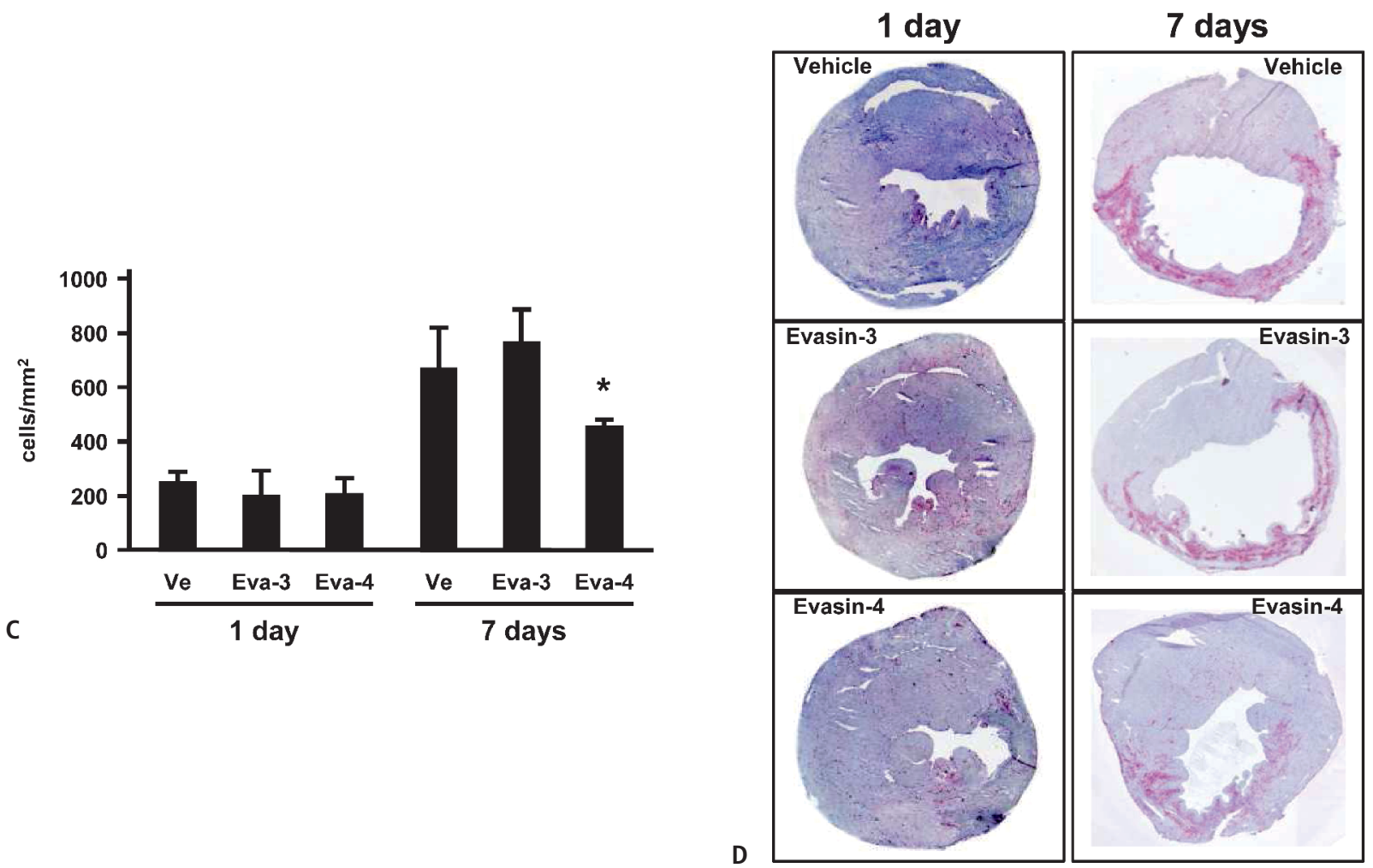
tion time per slice $2.5 \mathrm{~min}$ (18). The sequences were ECG and respiratory gated. Ejection fraction (EF) calculation was performed with the Osirix software (Open source http://www.osirix-viewer. $\mathrm{com} /$ ). The endocardial contour was dellineated by hand for systolic and diastolic phases, for each slice of the myocardium. EF (\%) was defined as (EDV-ESV)/EDV $\times 100$, where EDV is the enddiastolic volume and ESV the end-systolic volume. The segmentation as well as the EF measurement was blindly done by the same experimenter for all mice. The evaluation of the ventricle wall thickness and cavity area at mid papillary muscle level was done in short axis MR images using in-house software allowing calculation of wall thickness in 100 rays covering the whole left ventricle. This was performed after manually defining the endocardial and epicardial contours of the left ventricle. The mean thickness of the rays covering the septum and the lateral free-wall was evaluated at end-systole. The ratio septum-to-lateral thickness was also computed as previously described (19).

\section{Statistical analysis}

Statistics were performed with GraphPad Instat software version 3.05 (GraphPad Software, La Jolla, CA, USA). All results are expressed as mean \pm SEM. One-way ANOVA was used for multiple group comparison and two-tailed t-test (paired and unpaired) was used when appropriate for two group comparison. Survival analysis was tested using Kaplan-Meyer curves and the difference between the three groups were calculated using the Cox's F test given the relative limited sample size and the absence of censored data (3). P-values below 0.05 were considered significant.

\section{Results}

\section{Treatments with Evasin-3 or Evasin-4 reduce infarct size after $24 \mathrm{~h}$ of ischaemia}

We first evaluated the potential beneficial effects of treatments with Evasin-3 and Evasin-4 on infarct size in the mouse model of chronic myocardial ischaemia. Mice were treated with a single peritoneal injection of $10 \mu \mathrm{g}$ of Evasin-3, $1 \mu \mathrm{g}$ of Evasins- 4 or vehicle (PBS, $200 \mu \mathrm{l}) 5 \mathrm{~min}$ after the onset of the myocardial ischaemia. Infarct size was histologically measured by TTC staining after $24 \mathrm{~h}$ of ischaemia. Severity of the ischaemic insult was similar in

\footnotetext{
Figure 5: Treatments with Evasins reduce leukocyte infiltration in infarcted hearts during chronic ischaemia. Evasin-3 (Eva-3, $10 \mu \mathrm{g} / \mathrm{mouse}$ ), Evasin-4 (Eva-4, $1 \mu \mathrm{g} / \mathrm{mouse}$ ) or vehicle (Ve, $200 \mu \mathrm{l})$ were administered at $5 \mathrm{~min}, 24 \mathrm{~h}$ and $48 \mathrm{~h}$ after ischaemia onset. Data are expressed as mean \pm SEM ( $n=7-9$ per group). A) Quantification of infiltrated neutrophils per area in frozen sections of infarcted hearts at 1 and 7 days of chronic ischaemia. ${ }^{*} p<0.05$ vs vehicle. B) Representative images of neutrophil infiltration are shown. C) Quantification of infiltrated macrophages per area in frozen sections of infarcted hearts at 1 and 7 days of chronic ischaemia. ${ }^{*} p<0.05$ vs vehicle. D) Representative images of macrophage infiltration are shown.
}

the different groups, as shown by similar ratio of area at risk (AAR) relative to ventricle area $(\mathrm{V})(-$ Figure $1 \mathrm{~A})$. Both treatments with Evasin-3 or Evasin-4 induced a significant reduction in infarct size (I/AAR) when compared to PBS-treated mice ( $>$ Figure $1 \mathrm{~B}$ and $\mathrm{C})$.

\section{Treatments with Evasin-3 or Evasin-4 do not affect activation of protective intracellular pathways}

The potential activation of survival cardioprotective signalling pathways early during chronic ischaemia was investigated as a potential mechanism underlying Evasin-mediated benefits (20). As previously shown in mouse myocardial ischaemia/reperfusion model (7), the in vivo exposure of myocardium for 15 minutes of ischaemia was associated with a significant increase in ERK1/2 and Stat-3 (Tyr) phosphorylation as compared to sham-operated animals ( Figure 2A-E). On the other hand, no significant increase in Stat-3 (Ser) phosphorylation was induced by chromic ischaemia in Vehicle-treated as compared to sham-operated animals ( Figure 2D and F). No statistically significant effect was induced by each of Evasin treatment as compared to vehicle on different protective cardiac intracellular pathways investigated ( $>$ Figure 2A-F).

\section{Reduction in circulating levels of CXCL1 and CCL2 is associated with Evasin-4 treatment at day 1 of chronic ischaemia}

Circulating concentrations of both neutrophil (i.e. CXCL1) and macrophage (i.e. CCL2) chemoattractants were assessed at days 1 and 7 after ischaemia onset in the mouse groups. Confirming previously published results $(3,7,16)$, at day 1 , chronic cardiac ischaemia was associated with a significant increase in serum levels of CXCL1, CCL2, CXCL2, CCL5, as compared to sham-operated controls ( Figure 3A-D). No significant increase in CCL11 serum levels of infarcted mice was shown when compared to sham-operated animals ( Figure 3E) Treatment with Evasin-4, but not Evasin-3 was associated with the reduction of both CXCL1 and CCL2 serum levels as compared to control vehicle ( $>$ Figure $3 \mathrm{~A}$ and $\mathrm{B})$. At day 7 post-infarction, both anti-chemokine treatments were associated with abrogation of CXCL1 and CCL2 levels when compared to vehicle-treated animals ( $>$ Figure $3 \mathrm{~A}$ and $\mathrm{B}$ ). No significant effects on the levels of other chemokines (i.e. CXCL2, CCL5, CCL11) at both days 1 and 7 of chronic ischaemia was shown on Evasin-treated mouse serum as compared to $\mathrm{Ve}$ hicle ( Figure 3C-E). Finally, CCL3 serum levels were found undetectable (below the lower range of detection: $4.7 \mathrm{pg} / \mathrm{ml}$ ) in all mouse serum at days 1 and 7 after ischaemia onset (data not shown).

Considering that Evasin-3 and Evasin-4 were supposed to reduce the bioactivity (instead of the levels) of CXCL1/CXCL2 and $\operatorname{CCL} 5 / \operatorname{CCL} 11(7,9)$, respectively, we focused on the potential molecular mechanism underlying the unexpected cross-reduction in CXCL1 and CCL2 levels that was exclusively associated with Evasin-4 treatment at one day of chronic ischaemia. 


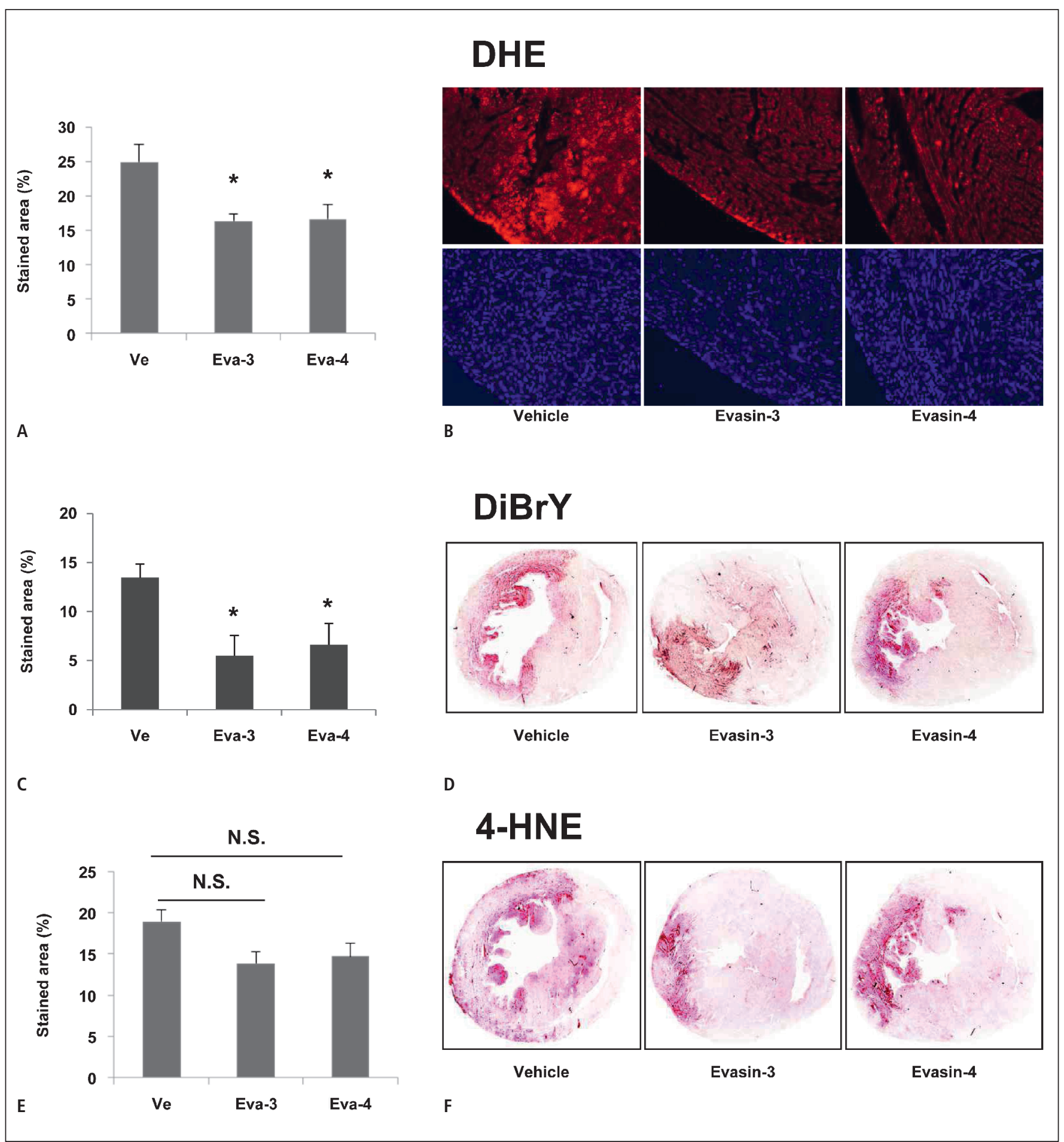

Figure 6: Treatment with Evasins reduced superoxide production in infarcted hearts at $\mathbf{2 4} \mathrm{h}$ of chronic ischaemia. A) Quantifications of superoxide (DHE staining) content in frozen sections of infarcted hearts at 24 $h$ of chronic ischaemia. Data are expressed as mean \pm SEM ( $n=4-6$ per group; ${ }^{*} p<0.05$ vs vehicle). B) Upper panel, representative images of DHE stained middle heart sections of vehicle (Ve)-, $10 \mu \mathrm{g} /$ mouse Evasin-3 (Eva-3)or $1 \mu \mathrm{g} /$ mouse Evasin-4 (Eva-4)-treated mice at $24 \mathrm{~h}$ of chronic ischaemia are shown. Lower panel, correspondent images of the same middle heart sections stained with 4',6-diamidino-2-phenylindole (DAPI), visualising nuclear DNA. C) Quantifications of 4-HNE staining content in frozen sections of in- farcted hearts at $24 \mathrm{~h}$ of chronic ischaemia ( $\mathrm{n}=4-5$ per group; p: N.S. [not significant]). D) Representative images of 4-HNE stained middle heart sections of vehicle (Ve)-, $10 \mu \mathrm{g} / \mathrm{mouse}$ Evasin-3 (Eva-3)- or $1 \mu \mathrm{g} / \mathrm{mouse}$ Evasin-4 (Eva4)-treated mice at $24 \mathrm{~h}$ of chronic ischaemia are shown. E) Di-bromo tyrosine (DiBrY) content in frozen sections of infarcted hearts at $24 \mathrm{~h}$ of chronic ischaemia. Data are mean \pm SEM ( $n=4$ per group; ${ }^{*} p<0.05$ vs vehicle). $F$ ) Representative images of DiBrY stained middle heart sections of vehicle (Ve)-, $10 \mu \mathrm{g} /$ mouse Evasin-3 (Eva-3)- or $1 \mu \mathrm{g} /$ mouse Evasin-4 (Eva-4)-treated mice at $24 \mathrm{~h}$ of chronic ischaemia are shown. 


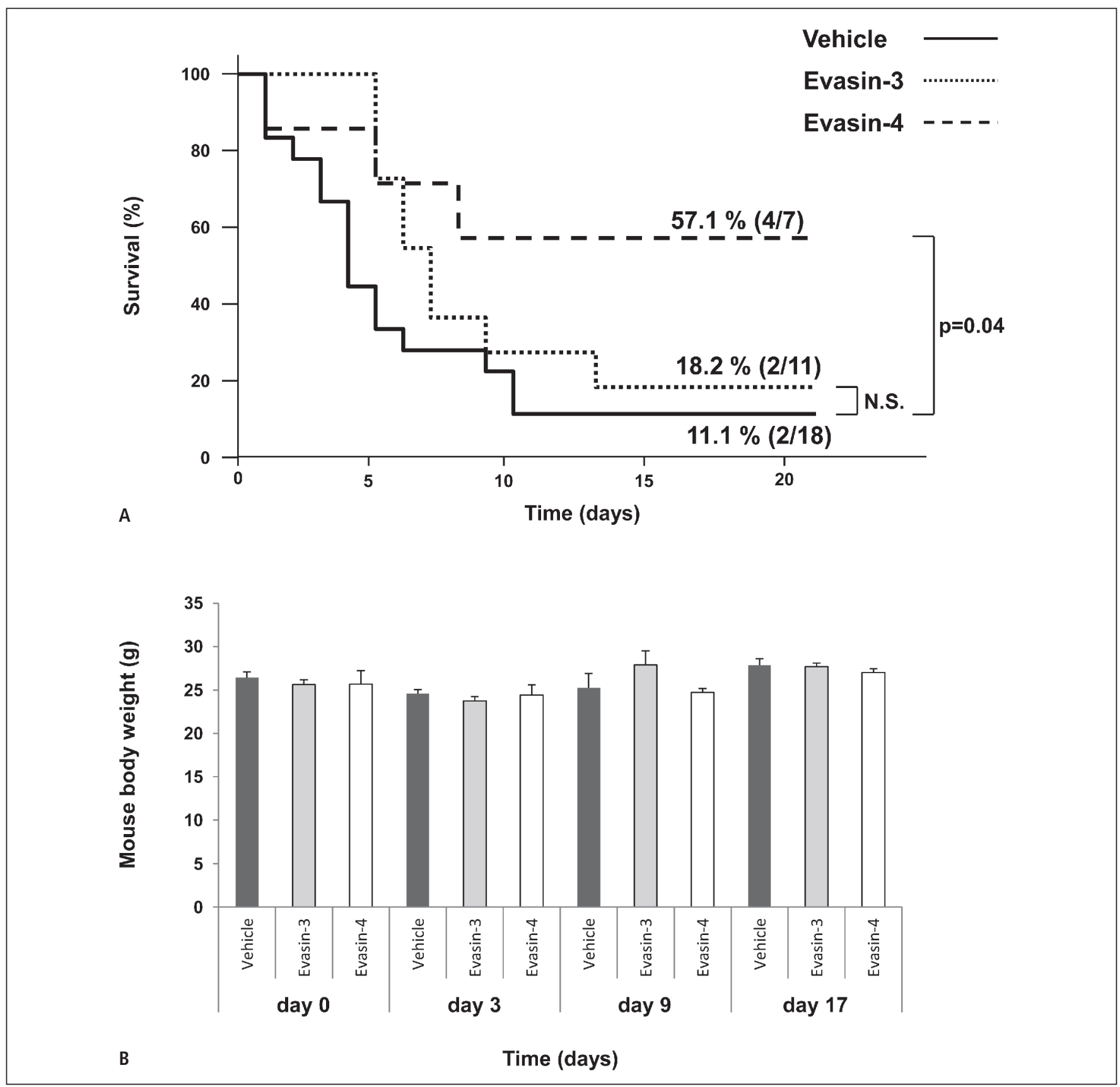

Figure 7: Treatment with Evasin-4 improves mouse survival during chronic myocardial ischaemia. A) Kaplan-Meier survival curve following myocardial infarction and permanent ischaemia in Vehicle-, Evasin-3- and Evasin-4-treated mice ( $n=7-18$ per group). N.S.: not significant. B) Body weight of vehicle- (black bars), Evasin-3- (gray bars) and Evasin-4- (white

As recently demonstrated (16), T lymphocytes are a major source of serum levels of chemokines in mice. Mitogen stimulation with PMA/Ionomycin induced a significant release of CCL5 in PBMCs ( $>75 \%$ CD3 + lymphocytes) as compared to control medium ( Figure 4A). In addition, stimulation with recombinant CCL5 significantly increased CXCL1 and CCL2 release ( $>$ Figure $4 \mathrm{~B}$ and $\mathrm{C}$ ) in PBMCs as compared to control medium. Sponta- bars) treated mice during permanent ischaemia (from the day of surgery [time 0] till 17 days of chronic ischaemia). Data are expressed as mean \pm SEM ( $n=3-11$ per group). Differences in body weight at any time points investigated and also between treatment groups were statistically not significant (N.S.).

neous cell death in PBMCs was about 10\% in control medium and about 25\% among cells treated with PMA-ionomycin, as previously reported (16). These findings showed a direct role of CCL5 in the synthesis of CXCL1 (neutrophil chemoattractant) and CCL2 (monocyte chemoattractant) by $\mathrm{T}$ lymphocytes. Therefore, we might hypothesize that Evasin-4 (blocking CCL5 bioactivity, but not Evasin-3 (inhibitor of CXCL1 and CXCL2 bioactivities) might 


\begin{tabular}{|c|c|c|c|c|c|}
\hline Measurements & $\begin{array}{l}\text { PBS-treated } \\
\text { mice }(n=9)\end{array}$ & $\begin{array}{l}\text { Evasin-3-treated } \\
\text { mice }(n=9)\end{array}$ & $\begin{array}{l}\text { p-value } \\
\text { (vs PBS) }\end{array}$ & $\begin{array}{l}\text { Evasin-4-treated } \\
\text { mice } \\
(n=9)\end{array}$ & $\begin{array}{l}\text { p-value } \\
\text { (vs PBS) }\end{array}$ \\
\hline \multicolumn{6}{|l|}{1 day } \\
\hline Total WBC ${ }^{*}$, no. x $10^{9} / l$ & $4.18 \pm 0.43$ & $4.47 \pm 0.64$ & 0.6990 & $3.94 \pm 0.57$ & 0.7474 \\
\hline Lymphocytes, no. x $10^{9} /$ & $2.07 \pm 0.79$ & $2.7 \pm 1.15$ & 0.2129 & $2.78 \pm 0.51$ & 0.2358 \\
\hline $\mathrm{RBC}$, no. $\times 10^{12} / \mathrm{I}$ & $8.66 \pm 0.23$ & $7.80 \pm 0.56$ & 0.1658 & $8.18 \pm 0.16$ & 0.1047 \\
\hline Platelets, no. x $10^{9} / /$ & $1102.6 \pm 59.19$ & $980.56 \pm 75.02$ & 0.2199 & $968.89 \pm 88.80$ & 0.2284 \\
\hline \multicolumn{6}{|l|}{7 days } \\
\hline Total WBC ${ }^{*}$, no. $\times 10^{9} / \mathrm{l}$ & $10.18 \pm 1.01$ & $7.66 \pm 0.92$ & 0.1033 & $6.60 \pm 2.78$ & 0.0558 \\
\hline Lymphocytes, no. x 109/l & $5.64 \pm 0.75$ & $5.68 \pm 0.58$ & 0.9710 & $4.08 \pm 0.37$ & 0.0998 \\
\hline RBCt, no. $\times 10^{12} / l$ & $7.42 \pm 0.26$ & $7.43 \pm 0.18$ & 0.9779 & $7.22 \pm 0.23$ & 0.5763 \\
\hline Platelets, no. x $10^{9} / \mathrm{l}$ & $1022.2 \pm 94.29$ & $1078.1 \pm 110.07$ & 0.7230 & $947.40 \pm 69.30$ & 0.5405 \\
\hline \multicolumn{6}{|c|}{ Data are expressed as mean \pm SEM. * WBC: white blood cells. $\dagger$ RBC: red blood cells. } \\
\hline
\end{tabular}

abrogate CCL5-induced release of CXCL1 and CCL2 by circulating $\mathrm{T}$ lymphocytes in mouse serum in vivo at day 1 of chronic ischaemia.

\section{Treatments with Evasin-3 or Evasin-4 reduce neutrophil infiltration after days 1 and 7 of chronic ischaemia}

Mice were treated with Evasin-3 (10 $\mu \mathrm{g} /$ mouse), Evasin-4 (1 $\mu \mathrm{g} /$ mouse) or vehicle (PBS, $200 \mu \mathrm{l})$ at $5 \mathrm{~min}, 24 \mathrm{~h}$ and $48 \mathrm{~h}$ after ischaemia onset. At both days 1 and 7 of chronic ischaemia, treatment with each Evasin abrogated neutrophil infiltration within infarcted hearts as compared to vehicle control ( $>$ Figure 5A and B). At day 1 of chronic ischaemia, treatment with Evasin-3 or Evasin-4 did not affect macrophage infiltration within infarcted hearts as compared to vehicle ( $>$ Figure $5 \mathrm{C}$ and $\mathrm{D}$ ). At day 7 , treatment with Evasin-4 (but not Evasin-3) reduced macrophage content within infarcted hearts when compared to control vehicle ( $>$ Figure $5 \mathrm{C}$ and $\mathrm{D}$ ).

\section{Treatments with Evasin-3 or Evasin-4 abrogate ROS production after day 1 of chronic ischaemia}

In order to identify a potential molecular mechanism underlying neutrophil-mediated cardiac injury (16), we focused on ROS release within infarcted hearts at day 1 of chronic ischaemia. Treatments with Evasin-3 and Evasin-4 significantly reduced superox- ide (DHE staining) and dibromotyrosine content when compared to control vehicle ( $>$ Figure $6 \mathrm{~A}-\mathrm{D}$ ). On the other hand, treatments with Evasins were not associated with significant improvements in 4-HNE production within infarcted hearts as compared to vehicle $(>$ Figure $6 \mathrm{E}$ and $\mathrm{F}$ ).

\section{Treatment with Evasin-4, but not Evasin-3 improves mouse survival during chronic ischaemia}

At 21 days of chronic ischaemia, mice treated with the Evasin-4 were characterised by a higher survival rate of $57.1 \%(4 / 7)$ when compared with mice treated with PBS (survival rate 11.1\%, 2/18, $\mathrm{p}=0.04$, Figure 7A). No significant improvements were associated with Evasin-3 treatment (survival rate 18.2\%, 2/11) when compared to control vehicle ( $>$ Figure $7 \mathrm{~A})$.

During chronic ischaemia, mice did not show any significant decrease in body weight ( $>$ Figure $7 \mathrm{~B}$ ), hematological parameters ( Table 1), suggesting that chronic treatments with Evasins did not affect food intake and blood cell homeostasis as compared to control vehicle.

\section{Treatments with Evasins are not associated with any improvements in post-infarction adverse cardiac remodelling during chronic ischaemia}

In order to identify the clinical cause of the improvement in mouse survival associated with Evasin-4 treatment, we focused on the

\begin{tabular}{l|l|l|l|l|l}
\hline Measurements & $\begin{array}{l}\text { PBS-treated mice } \\
(\mathbf{n}=5)\end{array}$ & $\begin{array}{l}\text { Evasin-3-treated mice } \\
(\mathbf{n}=5)\end{array}$ & $\begin{array}{l}\text { p-value } \\
(\mathbf{v s} \text { PBS) }\end{array}$ & $\begin{array}{l}\text { Evasin-4-treated } \\
\text { mice } \\
(\mathbf{n}=4)\end{array}$ & $\begin{array}{l}\text { p-value } \\
(\mathbf{v s} \text { PBS) }\end{array}$ \\
\hline Heart weight $(\mathrm{mg})$ & $191.6 \pm 21.5$ & $228.7 \pm 32.4$ & 0.3695 & $174.8 \pm 6.4$ & 0.5217 \\
\hline Body weight (g) & $27.8 \pm 0.8$ & $27.9 \pm 0.6$ & 0.8904 & $26.7 \pm 0.3$ & 0.2795 \\
\hline Data are expressed as mean \pm SEM.
\end{tabular}

Table 2: Heart and body weights at 21 days of chronic ischaemia. 
post-infarction adverse cardiac remodelling. At 21 days of chronic ischaemia, neither Evasin-3, nor Evasin-4 treatments did not influence mouse heart and body weight when compared to control vehicle ( Table 2). Accordingly, MRI determination of ejection fraction, left ventricular dimensions and wall thickness at 21 days did not shown any significant effect for both Evasins when compared to control PBS ( $>$ Table 3 , $>$ Figure 8 ). Transient statistically significant increase in end-systolic lateral wall thickness (for both Evasins), septum end-systolic thickness (exclusively for Evasin-3) and septum-to-lateral end-systolic wall thickness ration (exclusively for Evasin-4) were observed as compared to vehicle at day 1 of ischaemia ( Table 3, $\triangleright$ Figure 8). To further validate the effects of the exposure to a chronic ischaemia, at day 1 we showed a significant reduction in ejection fraction, end-systolic lateral wall thickness and increase end-systolic volume and septum-to-lateral end-systolic wall thickness as compared to age-matched wild-type mice without infarction ( $\$$ Table 3). Accordingly, at 21 days, chronic ischaemia was associated with significant reduction of ejection fraction and increase in end-systolic and end-diastolic volumes and septum-to-lateral end-systolic wall thickness ratio as compared to not infarcted wild-type mice ( Table 3). The marginal effect on post-infarction left ventricular adverse remodelling

Table 3: Magnetic resonance imaging (MRI) assessment of left ventricular dimension and wall thickness at mid papillary muscle level of mice without surgery (time 0 ) or at 1 and 21 days of chronic myocardial ischaemia.

\begin{tabular}{|c|c|c|c|c|c|c|}
\hline \multicolumn{7}{|c|}{ Left ventricular MRI measurements } \\
\hline \multicolumn{7}{|c|}{ Time 0 (no surgery) } \\
\hline Measurements & \multicolumn{6}{|c|}{ Wild type mice $(n=5)$} \\
\hline Ejection Fraction (\%) & \multicolumn{6}{|l|}{$53.97 \pm 2.56$} \\
\hline End-systolic volume (ml) & \multicolumn{6}{|l|}{$33.10 \pm 4.57$} \\
\hline End-diastolic volume (ml) & \multicolumn{6}{|l|}{$70.78 \pm 6.46$} \\
\hline End-systolic lateral wall thickness (mm) & \multicolumn{6}{|l|}{$1.45 \pm 0.06$} \\
\hline Septum end-systolic thickness (mm) & \multicolumn{6}{|l|}{$1.07 \pm 0.08$} \\
\hline $\begin{array}{l}\text { Septum-to-lateral end-systolic wall } \\
\text { thickness ratio }\end{array}$ & \multicolumn{6}{|l|}{$0.73 \pm 0.05$} \\
\hline \multicolumn{7}{|c|}{1 day of chronic ischaemia } \\
\hline Measurements & $\begin{array}{l}\text { PBS-treated } \\
\text { mice }(n=10)\end{array}$ & $\begin{array}{l}\text { p-value } \\
\text { (vs no surgery } \\
\text { time } 0 \text { ) }\end{array}$ & $\begin{array}{l}\text { Evasin-3-treated } \\
\text { mice }(n=10)\end{array}$ & $\begin{array}{l}\text { p-value } \\
\text { (vs PBS) }\end{array}$ & $\begin{array}{l}\text { Evasin-4-treated } \\
\text { mice }(n=7)\end{array}$ & $\begin{array}{l}\text { p-value } \\
\text { (vs PBS) }\end{array}$ \\
\hline Ejection Fraction (\%) & $29.17 \pm 2.98$ & 0.001 & $36.52 \pm 4.80$ & 0.315 & $35.91 \pm 3.43$ & 0.087 \\
\hline End-systolic volume (ml) & $55.87 \pm 4.5$ & 0.013 & $45.37 \pm 5.07$ & 0.151 & $41.99 \pm 5.80$ & 0.133 \\
\hline End-diastolic volume (ml) & $77.47 \pm 4.13$ & 0.310 & $70.20 \pm 3.72$ & 0.190 & $63.78 \pm 6.11$ & 0.055 \\
\hline End-systolic lateral wall thickness (mm) & $1.05 \pm 0.04$ & 0.001 & $1.34 \pm 0.06$ & 0.001 & $1.35 \pm 0.10$ & 0.033 \\
\hline Septum end-systolic thickness (mm) & $1.00 \pm 0.04$ & 0.594 & $1.13 \pm 0.03$ & 0.038 & $1.07 \pm 0.05$ & 0.305 \\
\hline $\begin{array}{l}\text { Septum-to-lateral end-systolic wall } \\
\text { thickness ratio }\end{array}$ & $0.95 \pm 0.04$ & 0.003 & $0.85 \pm 0.03$ & 0.089 & $0.81 \pm 0.04$ & 0.019 \\
\hline \multicolumn{7}{|c|}{21 days of chronic ischaemia } \\
\hline Measurements & $\begin{array}{l}\text { PBS-treated } \\
\text { mice }(n=4)\end{array}$ & $\begin{array}{l}\text { p-value } \\
\text { (vs no surgery } \\
\text { time } 0 \text { ) }\end{array}$ & $\begin{array}{l}\text { Evasin-3-treated } \\
\text { mice }(n=7)\end{array}$ & $\begin{array}{l}\text { p-value } \\
\text { (vs PBS) }\end{array}$ & $\begin{array}{l}\text { Evasin-4-treated } \\
\text { mice }(n=6)\end{array}$ & $\begin{array}{l}\text { p-value } \\
\text { (vs PBS) }\end{array}$ \\
\hline Ejection Fraction (\%) & $25.99 \pm 5.84$ & 0.0159 & $36.34 \pm 8.96$ & 0.646 & $33.29 \pm 7.58$ & 0.762 \\
\hline End-systolic volume (ml) & $156.56 \pm 55.85$ & 0.0159 & $94.26 \pm 30.33$ & 0.230 & $84.64 \pm 27.05$ & 0.257 \\
\hline End-diastolic volume (ml) & $199.67 \pm 62.12$ & 0.0159 & $126.97 \pm 26.95$ & 0.230 & $113.41 \pm 27.34$ & 0.257 \\
\hline End-systolic lateral wall thickness (mm) & $1.25 \pm 0.13$ & 0.2857 & $1.50 \pm 0.15$ & 0.164 & $1.38 \pm 0.13$ & 0.609 \\
\hline Septum end-systolic thickness (mm) & $1.13 \pm 0.12$ & 0.730 & $1.07 \pm 0.11$ & 0.648 & $1.28 \pm 0.04$ & 0.286 \\
\hline $\begin{array}{l}\text { Septum-to-lateral end-systolic wall } \\
\text { thickness ratio }\end{array}$ & $0.89 \pm 0.02$ & 0.016 & $0.72 \pm 0.06$ & 0.164 & $0.97 \pm 0.07$ & 0.610 \\
\hline
\end{tabular}




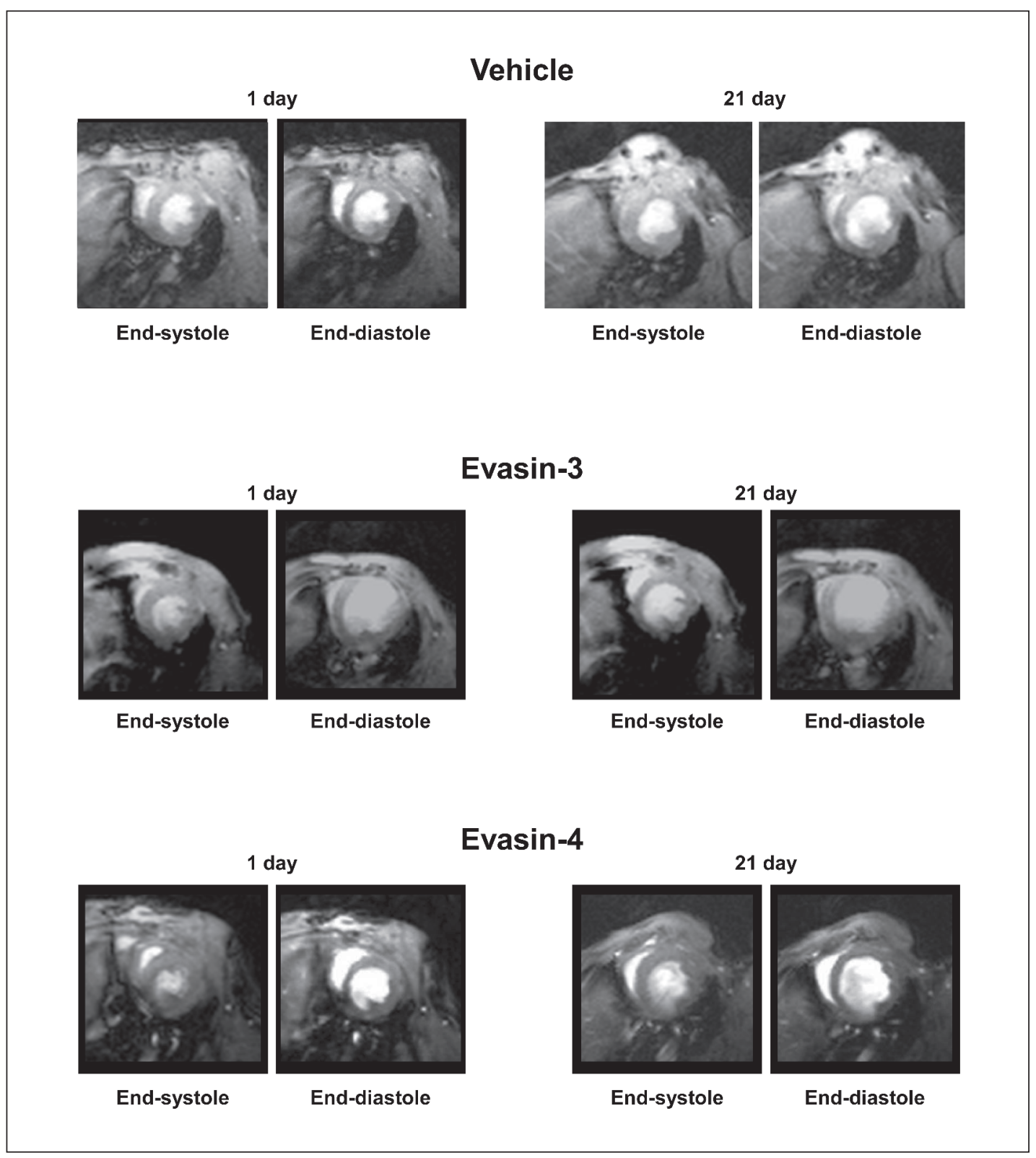

Figure 8: Treatments with Evasins do not affect cardiac function and adverse remodelling during chronic ischaemia. Representative magnetic resonance images (at end-systole and end-diastole) at mid papillary muscle level of Vehicle- and Evasin-3- and Evasin-4-treated mice at 1 and 21 days of the same animals during chronic ischaemia.

was confirmed by the lack of effect for both Evasins on wellknown active mediators of cardiac remodelling, such as matrixmetalloproteases (MMP-s) (3). In particular, treatments with both Evasins did not affect MMP-9 (24 h and day 7) and MMP-8 (day 7) myocardial content during chronic ischaemia as compared to control vehicle ( $>$ Figure 9A-C). Confirming the substantial lack of efficacy for treatments with Evasins on cardiac function and remodelling during chromic ischaemia, treatments with Evasins were not associated with any significant improvement on infarct size ( Figure 10A and B) and scar formation (collagen deposition, $>$ Figure $10 \mathrm{C}-\mathrm{F}$ ) at both days 7 and 21 after ischaemia onset when compared to control vehicle.
Figure 9: Treatments with Evasins do not affect MMP-9 and MMP-8 release in infarcted hearts during chronic ischaemia. A) Quantification of MMP-9 stained area in frozen sections of infarcted hearts at $24 \mathrm{~h}$ after chronic ischaemia onset. Data are expressed as mean \pm SEM ( $n=4$ per group). Right panel: Representative images of MMP-9 stainings at $24 \mathrm{~h}$ of chronic ischaemia are shown. B) Quantification of infiltrated MMP-9 stained areas in frozen sections of infarcted hearts at 7 days after chronic ischaemia onset. Data are expressed as mean \pm SEM ( $n=4-9$ per group). Right panel: Representative images of MMP-9 stainings at 7 days of chronic ischaemia are shown. C) Quantification of infiltrated MMP-8 stained areas in frozen sections of infarcted hearts at 7 days after chronic ischaemia onset. Data are expressed as mean \pm SEM ( $n=4-9$ per group). Right panel: Representative images of MMP-8 stainings at 7 days of chronic ischaemia are shown. Differences between treatment groups were statistically not significant (N.S.). 


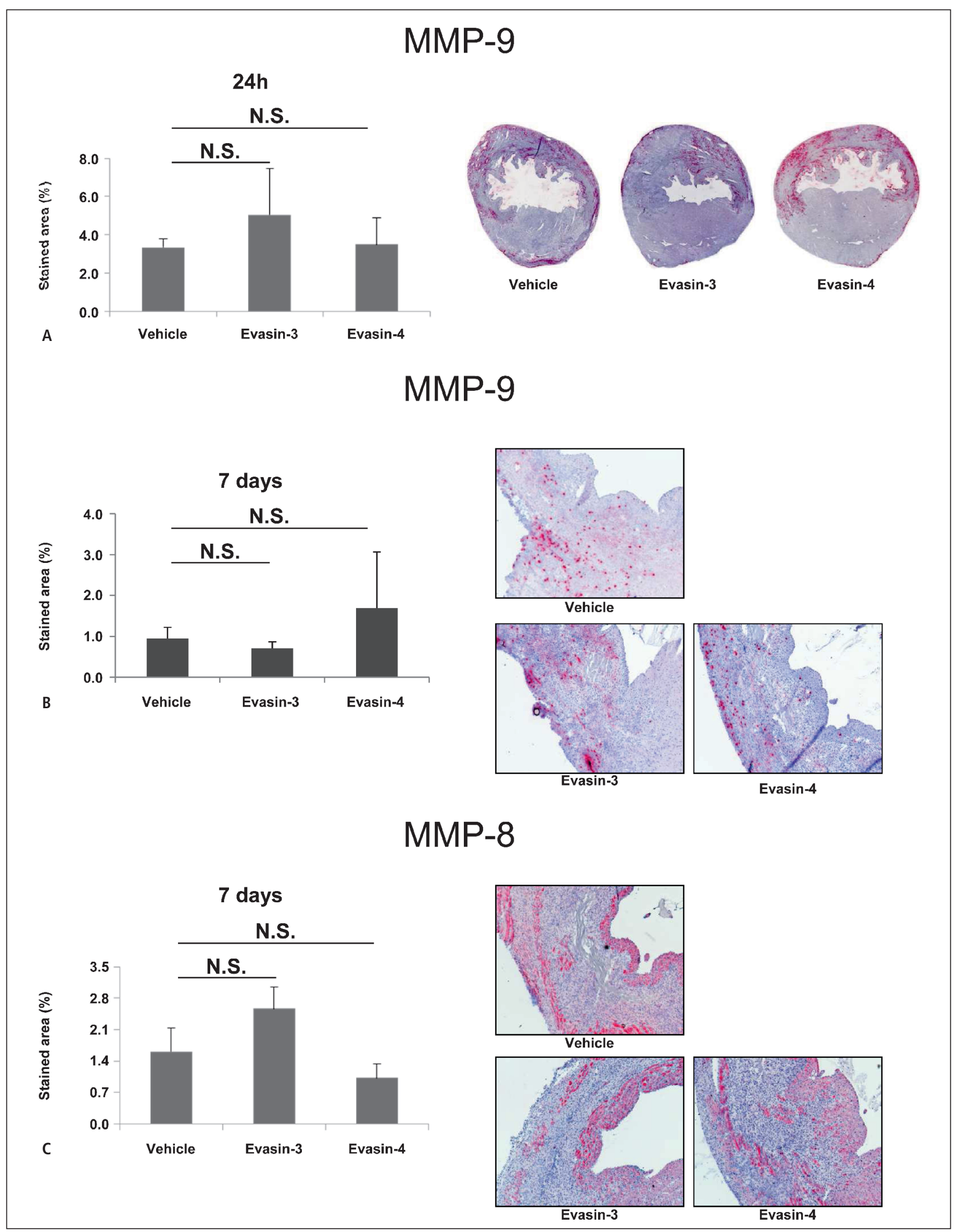




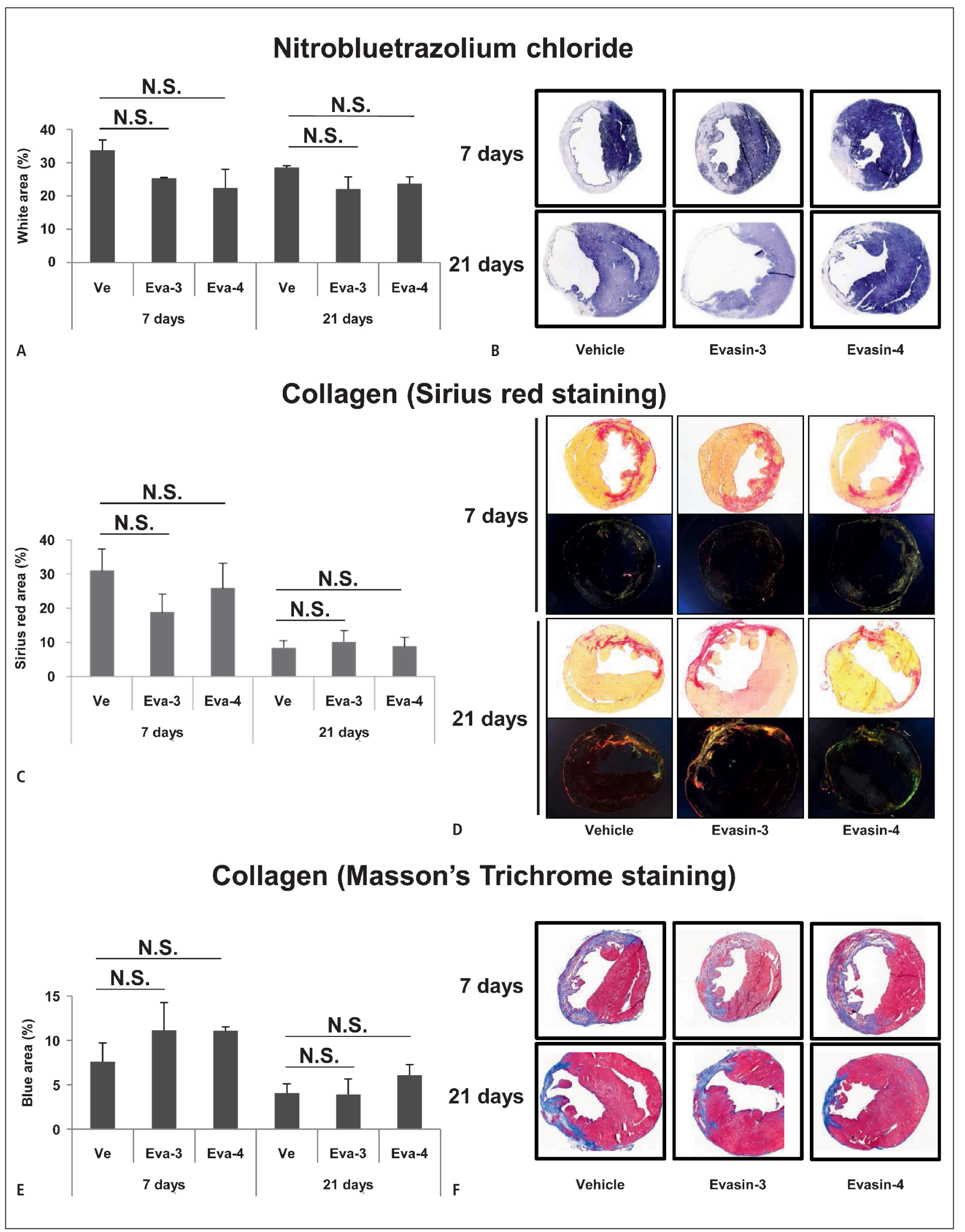




\section{Discussion}

An important result of this article is represented by the improvement on infarct size induced by a single injection of the CXC chemokine inhibitor Evasin-3 (7) or the broad spectrum CC chemokine antagonist Evasin-4 (9) in our mouse model of chronic myocardial ischaemia. In addition to being clinically relevant, these results confirm recent promising publications, showing that antichemokine treatments are potent cardioprotective strategies in animal models of acute and chronic myocardial ischaemia $(21,22)$. In fact, evidence by our research group using other anti-chemokine strategies recently showed that treatments selectively inhibiting CXCL1, CXCL2 or CCL5 were associated with remarkable improvements in post-ischaemic myocardial injury and inflammation $(3,7,23)$. Importantly, the selective inhibition of the bioactivity of these chemokines during the early inflammatory phase (first 3 days) was indicated as an effective approach to reduce infarct size and heart failure (3). As indicated by Liehn et al., the inflammatory phase after an acute myocardial infarction is characterised by the synthesis of multiple soluble mediators (including both dangerous and protective chemokines and cytokines), which differently determine the following wound healing and scar formation (21). In particular, inhibitory treatments selectively targeting neutrophil and macrophage chemoattractants exclusively during this first phase might block the deleterious effects of inflammation without altering the effects of cardioprotective inflammatory molecules and intracellular pathways $(7,21)$. In this study, we confirmed that treatments with Evasins did not affect the activation of myocardial salvation intracellular pathways not only during reperfusion after ischaemia (7), but also in a mouse model of chronic cardiac ischaemia. In addition, at $24 \mathrm{~h}$ of chronic ischae-

\footnotetext{
Figure 10: Treatments with Evasins do not affect collagen deposition and scar formation in infarcted hearts. A) Quantifications of nitrobluetrazolium chloride staining (differentiating between metabolically active and inactive tissues) in frozen sections of infarcted hearts of vehicle (Ve)-, 10 $\mu \mathrm{g} /$ mouse Evasin-3 (Eva-3)- or $1 \mu \mathrm{g} /$ mouse Evasin-4 (Eva-4)-treated mice at different time points of chronic ischaemia (days 7 to 21). Data are expressed as mean \pm SEM ( $n=3-6$ per group). B) Representative microphotographs of infarcted hearts showing nitrobluetetrazolium chloride staining (white coloured regions are metabolically inactive). C) Quantifications of Sirius red staining in frozen sections of infarcted hearts of vehicle (Ve)-, $10 \mu \mathrm{g} /$ mouse Evasin-3 (Eva-3)- or $1 \mu \mathrm{g} /$ mouse Evasin-4 (Eva-4)-treated mice at different time points of chronic ischaemia ( days 7 to 21). Data are expressed as mean \pm SEM ( $n=3-9$ per group). D) Representative microphotographs of infarcted hearts showing bright-field sections without polarisation (upper panel, red coloured regions are collagen) and corresponding sections under polarised light illumination (lower panel). E) Quantifications of Masson's Trichrome staining in frozen sections of infarcted hearts of vehicle (Ve)-, $10 \mu \mathrm{g} / \mathrm{mouse}$ Evasin-3 (Eva-3)- or $1 \mu \mathrm{g} /$ mouse Evasin-4 (Eva-4)-treated mice at different time points of chronic ischaemia (days 7 to 21). Data are expressed as mean \pm SEM ( $n=3-8$ per group). F) Representative microphotographs of infarcted hearts showing Masson's Trichrome staining (blue coloured regions are collagen). Differences between treatment groups were statistically not significant (N.S.) for all stainings.
}

mia, Evasin-4-mediated benefits on cardiac necrosis were associated with the concomitant reduction in CXCL1 and CCL2 serum levels. We recently showed that reduction in serum levels of neutrophil and monocyte/macrophage chemoattractants is strongly associated with improvements in the cardiac infiltration of these inflammatory cells after an acute ischaemia (16). The cellular mechanism identified was related to the reduction in the "random migration", implying that circulating leukocytes can migrate to inflamed tissues without following the "true" chemotactic tissue gradient (16). Accordingly, Evasin-mediated reduction in infarct size at $24 \mathrm{~h}$ of chronic ischaemia was positively associated with abrogation in neutrophil cardiac infiltration (at both days 1 and 7 from ischaemia onset) and the abrogation of ROS production (at day 1 of chronic ischaemia). As previously described $(7,16)$, the significant inhibition of ROS (both of leukocyte and cardiac origin) might represent the molecular mechanism underlying Evasinmediated protection. On the other hand, the effects of Evasin-3 and Evasin- 4 treatments on neutrophil infiltration (Evasin- 3 by inhibition of ELR-CXC chemokines, and Evasin- 4 by inhibition of CCR1 ligands since CCR1 participates in neutrophil recruitment in the mouse) were expected (24). Interestingly, we also showed that treatment with the broad spectrum inhibitor Evasin-4 (selectively blocking CCL 5 and CCL11 bioactivities) was also associated with the concomitant reduction of the serum levels of neutrophil chemoattractant (CXCL1) at both days 1 and 7 of chronic ischaemia. Those potent systemic effects were not observed for Evasin-3, indicating that the selective inhibition of CXC bioactivities does not affect circulating levels of other chemokines. These lower antiinflammatory properties of Evasin-3 were already observed in previous published animal models using both acute and chronic treatment protocols $(7,14)$. These results potentially indicate that in addition to their selective inhibitory activities, both Evasins might further reduce neutrophil recruitment within infracted hearts via an indirect abrogation of CXCL1 circulating levels. On the other hand, only Evasin-4 treatment was able to reduce cardiac macrophage content, whose recruitment is directly mediated by the activity of the CC chemokines CCL5 and CCL11. Our results also suggest that this effect might be partially due to the concomitant and prolonged serum level reduction of the macrophage chemoattractant CCL2 (observed at both days 1 and 7 after chronic ischaemia onset). In order to identify these potential unexpected molecular interactions between different chemokines (mainly under treatment with Evasin-4), we focused on CCL5 (a chemokine inhibited by Evasin-4 and up regulated during infarction [3]) and its potential activity to induce the release of CXCL1 and CCL2. Interestingly, 24 h-stimulation with CCL5 on T lymphocytes (that represent the major circulating leukocyte subsets in mice) (16) induced the release of both CXCL1 and CCL2. Considering that results on serum chemokine profile at $24 \mathrm{~h}$ of chronic ischaemia, we might speculate that the selective inhibition of CCL5 bioactivity by Evasin-4 during this period might also reduce both CCL2 and CXCL1 circulating levels by abrogating their secretion by circulating $\mathrm{T}$ lymphocytes in infarcted mice.

Taking together the results on infarct size and inflammation, we can suggest that Evasin-4 treatment can be considered as a 
more complete anti-inflammatory approach during chronic ischaemia (inhibiting not only neutrophil- but also macrophagemediated inflammation) as compared to Evasin-3, especially when considering the impact on mouse mortality discussed below. The key finding of this study is that, in top of the beneficial impact on myocardial infarct size, Evasin-4 infusion induced a significant reduction in mortality rate during chronic myocardial ischaemia as compared to control vehicle. These results partially confirm recent evidence by our research group on the protective role of CCL5 inhibition on post-infarction survival in mice (3). Conversely, no significant improvements were observed in Evasin-3-treated mice as compared control vehicle. This lack of efficacy of Evasin-3 treatment confirms recent findings from the research group of Dr. Liehn, showing that the selective blockade of CXCL1 might not prevent post-infarction inflammatory response, wound healing and scar formation in mice (25). In order to explain the potential mechanisms underlying the amelioration of this post-infarction outcome, we first focused on potential adverse effects due to chronic treatment with Evasins. Importantly, no significant abnormalities on mouse body weight and haematological parameters were observed in the mouse treatment groups, indicating that mouse mortality might be rather related to a cardiac cause. Then, we assessed histological (i.e. protease release, infarct size and collagen deposition) and MRI parameters of adverse cardiac remodelling and cardiac function. Also in this case, we did not detect any significant difference between animals treated with Evasins and control vehicle. These results were surprising, since we recently observed that CCL5 inhibition (using a chemokine neutralising antibody) was associated with improvements in both mortality and cardiac function in the same mouse model of chronic ischaemia (3). These results raise some concerns on potential compound-specific adverse effects for the different chemokine inhibitors. In both studies, we macroscopically checked potential alterations (such as cardiac rupture) at mouse autopsy. However, we did not observe any disorders associate with treatments and, thus, failed to identify the cardiac complications and reasons underlying

\section{What is known about this topic?}

- Chronic myocardial ischaemia is associated with the upregulation of systemic and myocardial inflammatory processes that are still unknown.

- Chemokines trigger leukocyte recruitment within the inflamed myocardium after an ischaemic injury.

\section{What does this paper add?}

- Selective inhibition of CCL5 bioactivities with Evasin-4 improves infarct size and survival in a mouse model of chronic myocardial ischaemia.

- Despite a potent anti-inflammatory activity, selective CXC chemokine inhibition with Evasin-3 is associated with reduction of infarct size without improving mouse survival. the differences on cardiac outcomes between Evasins treatments and anti-CCL5 antibody and Evasin-4 treatments (3). In particular, among the most frequent causes of post-infarction mortality, we were not able to investigate in both studies ([3], present study) the potential incidence of life-threatening cardiac arrhythmias by telemetry [26]. Considering that mice apparently well-tolerated the surgical protocol and did not present clinically important symptoms of heart failure (3), a reduction of this post-ischaemic complication might potentially explain Evasin-4-mediated benefits as compared to Evasin-3 or control vehicle. Interestingly, the role of circulating chemokines and their selective antagonists in cardiac arrhythmias has been poorly investigated (27). In particular, the product RO5657 (a CCR5 antagonist used as an anti-HIV treatment) has been shown to be pro-arrhythmogenic in cynomolgus monkeys via the inhibition of multiple cardiac channels (28). On the other hand, treatment with vicriviroc (another CCR5 antagonist) also in combination with HIV protease inhibitors was not shown to induce a clinically relevant QT prolongation in healthy humans (in a randomised phase I study) (29). A potential pro-arrhythmogenic effect of Evasin treatments was not assessed in our study. Thus, considering our technical concern, we have to admit the lack of the identification of the cause for different mortality rates as a main limitation of our study. Another important limitation might be the low number of mice used in this study essentially due to 3R (Reduce, Refine, Replace) criteria. Thus, additional studies (mainly using a second animal model of acute myocardial infarction) are needed to validate our preliminary results and potentially translate this anti-chemokine approach to humans.

In summary, this study showed that the selective inhibition of CC chemokines with Evasin-4 reduced cardiac injury/inflammation, ROS production and improved mouse survival. Despite a relevant anti-inflammatory activity, Evasin-3 treatment did not affect mouse survival. On the other hand, treatment with Evasins was well tolerated in mice and did not affect post-infarction adverse cardiac remodelling during chronic ischaemia. We concluded that the inhibition of CC chemokine bioactivities instead of CXC chemokines might represent a promising therapeutic approach to reduce post-infarction heart complications in mice (30).

\section{Acknowledgements}

This research was funded by EU FP7, Grant number 201668, AtheroRemo to Dr. F. Mach. This work was also supported by the Swiss National Science Foundation Grants to Dr. F. Mach (\#310030-118245), Dr N. Vuilleumier (\#310030-140736), and to Dr. F. Montecucco (\#32003B-134963/1). The research leading to these results has received funding from the European Community's Seventh Framework Programme TIMER [FP7-2007-2013] under grant agreement ${ }^{\circ}$ HEALTH-F4-2011-281608 to Dr. AE. Proudfoot. Dr. A. Nencioni is sponsored by the Italian Ministry of Health (grant GR-2008-1135635).

\section{Conflicts of interest}

None declared. 


\section{References}

1. Wang YT, Popović ZB, Efimov IR, et al. Longitudinal study of cardiac remodelling in rabbits following infarction. Can J Cardiol 2012; 28: 230-238.

2. Rösner A, Avenarius D, Malm S, et al. Persistent dysfunction of viable myocardium after revascularisation in chronic ischaemic heart disease: implications for dobutamine stress echocardiography with longitudinal systolic strain and strain rate measurements. Eur Heart J Cardiovasc Imaging 2012; 13: 745-755.

3. Montecucco F, Braunersreuther V, Lenglet S, et al. CC chemokine CCL5 plays a central role impacting infarct size and post-infarction heart failure in mice. Eur Heart J 2012; 33: 1964-1974.

4. Swirski FK, Nahrendorf M. Leukocyte behavior in atherosclerosis, myocardial infarction, and heart failure. Science 2013; 339: 161-166.

5. Steffens $\mathrm{S}$, Montecucco F, Mach F. The inflammatory response as a target to reduce myocardial ischaemia and reperfusion injury. Thromb Haemost 2009; 102: 240-247.

6. Frangogiannis NG, Smith CW, Entman ML. The inflammatory response in myocardial infarction. Cardiovasc Res 2002; 53: 31-47.

7. Montecucco F, Lenglet S, Braunersreuther V, et al. Single administration of the CXC chemokine-binding protein Evasin-3 during ischaemia prevents myocardial reperfusion injury in mice. Arterioscler Thromb Vasc Biol 2010; 30: 1371-1377.

8. Liehn EA, Tuchscheerer N, Kanzler I, et al. Double-edged role of the CXCL12/CXCR4 axis in experimental myocardial infarction. J Am Coll Cardiol 2011; 58: 2415-2423.

9. Déruaz M, Frauenschuh A, Alessandri AL, et al. Ticks produce highly selective chemokine binding proteins with antiinflammatory activity. J Exp Med 2008; 205: 2019-2031.

10. Frauenschuh A, Power CA, Déruaz M, et al. Molecular cloning and characterisation of a highly selective chemokine-binding protein from the tick Rhipicephalus sanguineus. J Biol Chem 2007; 282: 27250-27258.

11. Vieira AT, Fagundes CT, Alessandri AL, et al. Treatment with a novel chemokine-binding protein or eosinophil lineage-ablation protects mice from experimental colitis. Am J Pathol 2009; 175: 2382-2391.

12. Castor MG, Rezende B, Resende CB, et al. The CCL3/macrophage inflammatory protein-1alpha-binding protein evasin-1 protects from graft-versus-host disease but does not modify graft-versus-leukemia in mice. J Immunol 2010; 184: 2646-2654.

13. Russo RC, Alessandri AL, Garcia CC, et al. Therapeutic effects of evasin-1, a chemokine binding protein, in bleomycin-induced pulmonary fibrosis. Am J Respir Cell Mol Biol 2011; 45: 72-80.

14. Copin JC, da Silva RF, Fraga-Silva RA, et al. Treatment with Evasin-3 reduces atherosclerotic vulnerability for ischaemic stroke, but not brain injury in mice. J Cereb Blood Flow Metab 2013; 33: 490-498.

15. Westermann D, Mersmann J, Melchior A, et al. Biglycan is required for adaptive remodelling after myocardial infarction. Circulation 2008; 117: 1269-1276.
16. Montecucco F, Bauer I, Braunersreuther V, et al. Inhibition of nicotinamide phosphoribosyltransferase reduces neutrophil-mediated injury in myocardial infarction. Antioxid Redox Signal 2013; 18: 630-641.

17. Delattre BM, Braunersreuther V, Gardier S, et al. Manganese kinetics demonstrated double contrast in acute but not in chronic infarction in a mouse model of myocardial occlusion reperfusion. NMR Biomed 2012; 25: 489-497.

18. Delattre BM, Van De Ville D, Braunersreuther V, et al. High time-resolved cardiac functional imaging using temporal regularisation for small animal on a clinical 3t scanner. IEEE Trans Biomed Eng 2012; 59: 929-935.

19. Sipola P, Magga J, Husso M, et al. Cardiac MRI assessed left ventricular hypertrophy in differentiating hypertensive heart disease from hypertrophic cardiomyopathy attributable to a sarcomeric gene mutation. Eur Radiol 2011; 21: 1383-1389.

20. Lecour S, James RW. When are pro-inflammatory cytokines SAFE in heart failure? Eur Heart J 2011; 32: 680-685.

21. Liehn EA, Postea O, Curaj A, et al. Repair after myocardial infarction, between fantasy and reality: the role of chemokines. J Am Coll Cardiol 2011; 58: 2357-2362.

22. Kanzler I, Liehn EA, Koenen RR, Weber C. Anti-inflammatory therapeutic approaches to reduce acute atherosclerotic complications. Curr Pharm Biotechnol 2012; 13: 37-45.

23. Braunersreuther V, Pellieux C, Pelli G, et al. Chemokine CCL5/RANTES inhibition reduces myocardial reperfusion injury in atherosclerotic mice. J Mol Cell Cardiol 2010; 48: 789-798.

24. Liehn EA, Merx MW, Postea O, et al. Ccrl deficiency reduces inflammatory remodelling and preserves left ventricular function after myocardial infarction. J Cell Mol Med 2008; 12: 496-506.

25. Oral H, Kanzler I, Tuchscheerer N, et al. CXC chemokine KC fails to induce neutrophil infiltration and neoangiogenesis in a mouse model of myocardial infarction. J Mol Cell Cardiol 2013; Epub ahead of print.

26. Kochs M, Eggeling T, Hombach V. Pharmacological therapy in coronary heart disease: prevention of life-threatening ventricular tachyarrhythmias and sudden cardiac death. Eur Heart J 1993; 14 (Suppl E): 107-119.

27. Elmas E, Lang S, Dempfle CE, et al. High plasma levels of tissue inhibitor of metalloproteinase-1 (TIMP-1) and interleukin-8 (IL-8) characterize patients prone to ventricular fibrillation complicating myocardial infarction. Clin Chem Lab Med 2007; 45: 1360-1365.

28. Misner DL, Frantz C, Guo L, et al. Investigation of mechanism of drug-induced cardiac injury and torsades de pointes in cynomolgus monkeys. Br J Pharmacol 2012; 165: 2771-2786.

29. O'Mara E, Kasserra C, Huddlestone JR, et al. Effect of vicriviroc on the QT/corrected QT interval and central nervous system in healthy subjects. Antimicrob Agents Chemother 2010; 54: 2448-2454.

30. Landmesser U, Wollert KC, Drexler H. Potential novel pharmacological therapies for myocardial remodelling. Cardiovasc Res 2009; 81: 519-527. 